Preprints of the

Max Planck Institute for

Research on Collective Goods

Bonn 2013/11

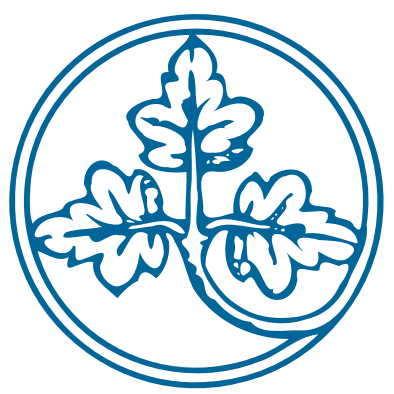

How Voice Shapes Reactions to Impartial Decision-Makers: An Experiment on Participation Procedures

Marco Kleine

Pascal Langenbach

Lilia Zhurakhovska

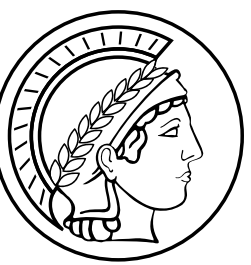




\title{
How Voice Shapes Reactions to Impartial Decision- Makers: An Experiment on Participation Procedures
}

\author{
Marco Kleine / Pascal Langenbach / Lilia Zhurakhovska
}

July 2013

revised version February 2017 


\title{
How Voice Shapes Reactions to Impartial Decision-Makers: An Experiment on Participation Procedures
}

\author{
Marco Kleine $^{\star} \quad$ Pascal Langenbach $^{\S} \quad$ Lilia Zhurakhovska $^{\dagger}$
}

\begin{abstract}
This paper studies how participation in decision procedures affects people's reactions to the deciding authority. In our economic experiment, having voice, i.e., the opportunity to state one's opinion prior to a decision, significantly increases subordinates' subsequent kindness towards the authority. These positive effects occur irrespectively of the decisions' content. The experimental findings stress the positive effects of voice when subordinates and authorities interact. Our results suggest that in organizations, but also in the legal and political arena, participative decision-making can be used to guide people's actions after decisions have been taken.
\end{abstract}

Key words: voice, participative decision-making, communication, laboratory experiment

JEL: C91, D03, D23, D63, K40

Max Planck Institute for Innovation and Competition, Munich, Germany, marco.kleine@ip.mpg.de

$\S \quad$ Max Planck Institute for Research on Collective Goods, Bonn, Germany, langenbach@ coll.mpg.de

$\dagger \quad$ University of Duisburg-Essen (Mercator School of Management), Lotharstr. 65, 47057 Duisburg, Germany, lilia.zhurakhovska@uni-due.de (corresponding author) 


\section{Introduction}

People are often confronted with unilateral decisions of authorities, which profoundly affect their lives. For instance, consider a worker whose boss decides how to allocate yearly bonuses among the team members. Alternatively, imagine a court decision: a judge decides a case where a defendant is sued by his neighbor. A common characteristic of both situations lies in the fact that the authority makes her ${ }^{1}$ decisions irrespectively of the subordinates' consent. Nevertheless, it is important that the authority remains respected by the subordinate and that the decision is acceptable even if decisions turn out unfavorable. How much effort would the worker spend on his work in the next bonus cycle? Would the defendant who lost in court try to fight the decision? Ultimately, answers to these questions might also depend on the subordinate's evaluation of the decision and the decision-maker.

Subordinates' participation in decision processes could be an effective way to ensure their cooperation. As a weak form of participation, subordinates often get the chance to present their arguments prior to the decision. Such participation through having "voice" (cf. Hirschman, 1970; Folger, 1977) is, for example, at the core of legal decision-making procedures. It is often referred to as the parties' right to be heard. Participation through voice is also common practice in organizations.

Classical economic theory assumes that people are only motivated by the outcomes of decisions. Consider the two examples above: A homo economicus worker would only care about his share of the yearly bonus. For the defendant in court, it would only be important whether he wins or loses his case. However, there is growing evidence in the economic literature that besides outcomes people also care about the way by which these outcomes are reached (e.g., Bolton et al., 2005; Brandts and Charness, 2003; Dold and Khadjavi, 2016; Frey et al., 2001; Frey et al., 2004; Frey and Stutzer, 2005; Ku and Salmon, 2013; and Trautmann, 2009). ${ }^{2}$

This paper provides causal evidence from a laboratory experiment on how participation in the decision-making process by presenting one's views affects subordinates' evaluations of decision-makers. More specifically, we infer these evaluations from subordinates' post-decision kindness towards decision-makers in a dictator game. Having in mind the decision tasks, e.g., of judges and referees, but also of managers in some situations, our paper is concerned with the relationships between subordinates and impartial authorities. Therefore, we study a stylized setting in which the ideal of "just" decision-making is pursued. This is a setting in which the decision-maker has no monetary stakes in the outcome of the decision.

1 Throughout the paper, the feminine form is used for the authority (decision-maker; player A) and the masculine form for the subordinates (players $\mathrm{Y}$ and $\mathrm{X}$ ).

2 While research on procedures in economics is still in its early stages, the effects of procedures on people's evaluations have been the main focus of the research on procedural justice in social psychology (see the seminal work of Thibaut and Walker, 1975; Lind and Tyler, 1988, for an early review of the literature). 
Our experiment consists of several parts and subjects are only informed about the content of each part just before the respective part starts. In the first part, the decision-maker has to settle a conflict between two subordinates, i.e., she allocates money between them. In two voice treatments, one subordinate expresses his opinion about a fair allocation towards the decisionmaker. The voice treatments differ in the extent of the participation opportunity, while in the baseline no participation is possible. In the second part, one subordinate is the sender in a dictator game, with the decision-maker being the receiver. In the voice treatments, this dictator is the subordinate who had been given the voice opportunity in the first part. Feedback about the decision-maker's allocation decision is only given at the end of the experiment. Therefore, using the strategy method (Selten, 1967), the subordinate makes his transfer decision in the dictator game conditional on any possible allocation from the first part. The transfer in the dictator game is our main variable of interest. We interpret this transfer as a general measure for the subordinate's evaluation of the decision-maker. Hence, the differences in transfers are the measure for the effect of voice. ${ }^{3}$

We find strong treatment differences in subordinates' transfers in the post-decision dictator game. Subjects in both voice treatments send significantly more money to the decision-maker than in the baseline. On average, transfers increase by $90 \%$. Most interestingly, this positive effect on transfers is largely independent of allocation decisions in the first part of the experiment. It even holds for unfavorable outcomes, when it becomes obvious that the voice opportunity did not positively influence outcomes. Furthermore, we find no differences in transfers across the two voice treatments, indicating that the extent of voice is not decisive for the positive effect to persist. Exploratory analyses reveal that the reactions of female participants largely drive the effect of voice.

The findings of this paper highlight the importance of voice for the design of decision procedures when impartial decision-makers and subordinates interact. This suggests that decisionmakers such as referees in sports, judges and juries in courts, ombudsmen in business organizations, or editors of journals may rely on voice procedures to get support for their decisions.

To date, economic research has mainly focused on the effects of voice on decision-makers; ${ }^{4}$ only few papers have explicitly tested how voice affects the behavior of those who have voice. ${ }^{5}$ Corgnet and Hernán-González (2013) find that voice fosters positive or negative recip-

3 Note that this paper studies subordinates' reactions to the voice procedure. These reactions are elicited in part two of the experiment. The effects of the voiced fairness opinions on the impartial decision-makers' allocation decisions (see part one of the experiment) are analyzed in Kleine et al. (2016).

4 For example, the dictator game is used to study the effects of voice on the decision-makers' kindness (see Andreoni and Rao, 2011; Charness and Rabin, 2005; Mohlin and Johannesson, 2008; Rankin, 2006; and Yamamori et al., 2008).

5 Stronger forms of participation beyond the expression of opinion have been studied more extensively. E.g., in a labor context, Charness et al. (2012) document a positive effect of the agents' opportunity to decide about their own wages on their effort provision (see also Köhler et al., 2015). Inversely, Falk and Kosfeld (2006) provide experimental evidence that limiting the choice set of agents may reduce the willingness to provide effort. The literature on social dilemmas has established a positive effect of participation via voting over rules of the game on the willingness to cooperate (e.g., Dal Bó et al., 2010; Markussen et al., 2014; and Tyran and Feld, 2006). 
rocal reactions - depending on whether decision-makers follow the voiced suggestions. Ong et al. (2012) study an ultimatum game setting and show that voicing an opinion to the experimenter decreases the minimum amount responders are willing to accept. However, they further show that voice towards the proposer increases the minimum amount that responders accept (cf. Ong et al., 2013). Rankin (2003) reports ultimatum game results in which the overall rejection rates increase in a treatment with prior requests of responders towards proposers, but, controlling for offered amounts, the probability of a rejection decreases.

Conceptually, our study extends this research on voice in two ways. First, previous experiments focused on the reactions to self-interested decision-makers, whereas our paper is concerned with impartial decision-makers. The ideal of impartial decision-making occurs in many economic, legal, or political interactions where fair or just decisions are required. Second, we study behavior in a non-bargaining situation. Decision-makers do not have to rely on the subordinates' consent and make their decision unilaterally.

Moreover, our experiment is particularly suited to study the effects of voice for favorable as well as unfavorable decisions. We find that, in the interaction with decision-makers who are required to act impartially, the effect of voice is unanimously positive. This is distinct from the effect of voice towards self-interested decision-makers (Corgnet and Hernán-González, 2013; Ong et al., 2012; but see Rankin, 2003). Lastly, our paper shows gender differences in behavior due to participation procedures.

For the remainder of the paper, we proceed as follows: We explain our experimental design in detail in section 2, derive our behavioral predictions in section 3, and report the results in section 4. In two additional treatments (in section 5), we further elaborate on the mechanisms behind the voice effect. Section 6 briefly summarizes and discusses the results.

\section{Experimental Design and Procedure}

\subsection{The experiment}

Table 1 gives an overview of the experimental design. The experiment consists of three parts. Subjects know that there will be several parts, but receive specific information about the content of each part only immediately before playing the relevant part of the experiment. Subjects are informed about the other participants' decisions and about any earnings only at the end of the experiment. However, they are explicitly told that they cannot lose money they have earned in a previous part in any of the subsequent parts. In the experiment, we use an experimental currency unit (ECU). ${ }^{6}$ All instructions are read out aloud by the experimenter immediately before the relevant part to achieve common knowledge about the procedure. ${ }^{7}$

6 The currency is called "Taler" in the experiment.

7 See Appendix B for an English translation of the instructions. 
Table 1

Experimental Design

\begin{tabular}{|ll||}
\hline Part 1: & Real-effort task by players $\mathrm{X}$ and $\mathrm{Y}$ with asymmetric workload and piece rate \\
& Treatment variation: player $\mathrm{X}$ sends / does not send a message to player $A$ \\
& $-\quad$ baseline: no message \\
& $-\quad$ narrow voice: statement about a fair allocation \\
& $-\quad$ ited to 800 characters) \\
& Allocation decision by impartial player $\mathrm{A}$ \\
\hline Part 2: & (Unannounced) dictator game with player $\mathrm{X}$ as dictator and player $\mathrm{A}$ as re- \\
& ceiver (strategy method for all 21 possible allocations from part 1) \\
\hline Part 3: & Belief elicitation of players $\mathrm{X}$ and $\mathrm{Y}$ about chosen allocation by player $\mathrm{A}$ in \\
& part 1
\end{tabular}

At the beginning of the experiment, each subject is randomly assigned one of the three roles A, X, or Y. Players keep their roles across the three parts of the experiment. Subjects are then matched in groups of three, with one player from each role.

\section{Part 1:}

In part 1, players $\mathrm{X}$ and $\mathrm{Y}$ complete a real-effort task of counting zeros on a screen of zeros and ones (see Abeler et al., 2011). Size and difficulty of the screens are identical, but the number of screens to be solved and the piece rate differs between players $\mathrm{X}$ and Y. Player X has to solve 12 tables, while player $\mathrm{Y}$ has to solve only 4 tables. Player X realizes $150 \mathrm{ECU}$ per screen, while player Y realizes only 50 ECU per screen. Players cannot move to the next part unless they have completed their task. Thus, player X contributes 1800 ECU and player Y contributes 200 ECU to an amount of 2000 ECU generated in total. We chose an asymmetric workload and piece rate to induce a normative conflict (cf. Konow, 2000; Nikiforakis et al., 2012; and Reuben and Riedel, 2013) among players. Thus, we provide arguments for differing opinions about a fair allocation of the 2000 ECU between players X and Y. Focal normative rules which could be considered by the players as fair are equity output (players $\mathrm{X}$ and $\mathrm{Y}$ deserve an allocation according to the ECU they produce, i.e., 1800 ECU for player X and 200 for player $Y$ ), equity input (players $X$ and $Y$ deserve an allocation according to the number of tasks they solve, i.e., 1500 ECU for player X and 500 ECU for player Y), and equality (equal split of the amount of money, i.e., $1000 \mathrm{ECU}$ for player $\mathrm{X}$ and $1000 \mathrm{ECU}$ for player Y). With the different fairness rules, we give meaning to the subsequent voice procedure and enhance the external validity of the allocation task, as player A fulfills a typical task of legal authorities by delivering a "just" solution between conflicting interests. 
Player A, who will later decide about the actual allocation, is not involved in the real-effort task. After completing the task, all three players indicate in private which allocation of the total amount between player $\mathrm{X}$ and player $\mathrm{Y}$ they would consider as fair. It is made explicit that this information will not be revealed to the other players and has no influence on the earnings of the players.

The next step is subject to our treatment variation. In the treatments broad voice and narrow voice, player X sends a message to player $\mathrm{A}$. In the narrow voice treatment, player X states to player A which allocation he would consider as fair. In addition to the stated number, in the broad voice treatment, player $\mathrm{X}$ can send a written message (limited to 800 characters) to player A. In the baseline, no messages are sent. In no treatment can players $\mathrm{Y}$ or A send a message. $^{8}$

Finally, player A is asked to allocate the amount of 2000 ECU between players X and $\mathrm{Y}$ "in a fair way". Her decision is confined to 21 possible allocations in steps of 100 ECU (from player X receiving $2000 \mathrm{ECU}$ and player $\mathrm{Y}$ receiving $0 \mathrm{ECU}$ to player $\mathrm{X}$ receiving $0 \mathrm{ECU}$ and player Y receiving 2000 ECU). Player A is impartial in her decision-making: she receives a lump-sum payment of 5 Euro (equivalent to 1000 ECU). Therefore, her decision does not influence her payoffs in the first part. Furthermore, later parts of the experiment cannot influence her allocation decision because their content is only announced after decisions in part 1 were taken.

\section{Part 2:}

In part 2, player $\mathrm{X}$ receives an additional endowment of $1000 \mathrm{ECU}$ and plays a dictator game (Forsythe et al., 1994) with player A as the receiver. Player X can transfer any integer amount up to 1000 ECU to player A. At this point, player X does not know the actual allocation decision by player A in the first part. Using the strategy method (Selten, 1967), player X indicates his transfer for each of the 21 possible allocations in the first part. At the end of the experiment, only the transfer corresponding to the actual decision of player A is realized.

\section{Part 3:}

In the third part, we elicit incentivized beliefs (expectations) of players $\mathrm{X}$ and $\mathrm{Y}$ about the allocation chosen by player A in the first part. For a correct guess, a player receives $200 \mathrm{ECU}$; for a guess that deviates from the actual allocation by one step only, he receives 50 ECU. If the guess deviates further from the actual allocation, the player does not receive any additional earnings in this part.

8 We restrict the voice opportunity to player $\mathrm{X}$ to elicit the mere effect of voice, irrespective of other strategic considerations. If player Y also had this possibility, this would have induced beliefs about the other player's message for player X. It would have introduced a strategic component of voice and uncertainty about the effectiveness of player X's message in comparison to player Y's message. 
The three parts are played only once. After part 3, subjects learn the payoff-relevant decisions of the other players and their earnings. The players' earnings are calculated as follows:

- Earnings of player $\mathrm{A}=$ lump-sum payment from part $1+$ transfer from player $\mathrm{X}$ in part 2

- Earnings of player $\mathrm{X}=$ amount allocated by player A in part $1+1000 \mathrm{ECU}-$ transfer to player $\mathrm{A}$ in part $2+$ earnings from the belief elicitation

- Earnings of player $\mathrm{Y}=$ amount allocated by player $\mathrm{A}$ in part $1+$ earnings from the belief elicitation

\subsection{Post-experimental test and questionnaires}

After the second part, players $\mathrm{X}$ and $\mathrm{Y}$ additionally indicate for every possible allocation how satisfied they would be with the allocation. At the end of the experiment, we elicit participants' social value orientations as control variables by applying a standard test by McClintock and Liebrand (1988). Furthermore, all subjects answer non-incentivized questionnaires, including inter alia questions about the perceived fairness of the allocation and the procedure, as well as demographics. ${ }^{9}$

\subsection{Procedure}

The experiment was conducted at the Cologne Laboratory for Economic Research using zTree (Fischbacher, 2007). 264 participants were recruited via ORSEE (Greiner, 2015) from the subject pool of the laboratory. 87 subjects participated in the narrow voice treatment as well as in the baseline (29 independent observations each) and 90 subjects participated in the broad voice treatment (30 independent observations). Participants were mainly students from various disciplines ( $40 \%$ majoring in economics) with a mean age of 24.80 years $(s d=5.18)$. $56 \%$ were female. Sessions lasted approximately 90 minutes on average. The experimental currency was converted into Euro $(2 \mathrm{ECU}=0.01 \mathrm{EUR})$ at the end of the experiment and paid out in cash. Participants earned $14.7 \mathrm{EUR}^{10}$ on average $(\mathrm{sd}=3.0)$, including a show-up fee of 4 EUR. 


\section{Behavioral Predictions}

Our main variable of interest is the transfer by player $\mathrm{X}$ in the dictator game as a measure for the player's evaluation of the impartial decision-maker. In particular, we are interested if and how the opportunity for voice in the previous allocation decision independently changes the subordinate's behavior towards the decision-maker in the subsequent dictator game.

Applying the standard assumptions of rational and self-interested players, predictions for transfers in the dictator game are straightforward: independently of the treatment and the possible allocation in the first part, player $\mathrm{X}$ will not transfer any money to the impartial decisionmaker. However, a vast body of experimental literature on dictator games has shown that transfers are common in such a non-strategic setting (for a meta-study, see Engel, 2011). We are interested in finding out how our treatment variations of voice towards the impartial decision-maker affect the giving behavior and whether this effect depends on the allocation chosen in part 1.

Our hypotheses relate to the psychological literature on procedural justice, which studies the instrumental and non-instrumental functions of voice (e.g., Lind et al., 1990; Shapiro and Brett, 1993; Tyler et al., 1985): According to the non-instrumental function people derive utility from the mere fact that they can state their opinion even without influencing outcomes (see Lind and Tyler, 1988 for an explanation of this effect). On the contrary, voice can be attributed an instrumental function. This implies that people value voice mainly because of its effects on decision outcomes (in the procedural justice literature, this view is traced back to Thibaut and Walker, 1975, 1978).

If the non-instrumental function prevails in our setting, positive effects of voice on subordinates' subsequent behavior should occur irrespectively of the previous decision of the impartial decision-maker. In economic experiments, behavior in line with a non-instrumental function can be found in the ultimatum game. Responders accept lower offers more frequently when they can express themselves even without any chance to influence decisions, e.g., after the decision has been made (Xiao and Houser, 2005) or to the experimenter prior to the decision (Ong et al., 2012). Thus, we should expect the following hypothesis to hold (see e.g., Folger et al., 1979 for evidence from the psychological literature): 
Hypothesis 1a: Transfers from players $X$ to the impartial decision-makers in part two are generally higher in both voice treatments than in the baseline. Also, transfers in the voice treatments are higher than in the baseline for every possible allocation chosen in part one.

This hypothesis is also supported by "mild" versions of the instrumental motivation if, for example, subordinates value the mere ex-ante opportunity to influence outcomes (see Shapiro, 2001).

However, following the logic of the instrumental explanations, it is argued that people want their voice to matter and that such a motivation may cause negative reactions when expectations are not met (Ong et al., 2012; see Folger, 1977). Evidence for the negative effect of voice has also been found in the ultimatum game when responders can send requests to the proposer before she makes her decision. This voice opportunity increases the minimum amount responders are willing to accept (Ong et al., 2012; but see Rankin, 2003). ${ }^{11}$ If the negative effect predominantly determines subordinates' behavior in our setting, the direction of the consequences of voice will depend on the favorability of the allocation in the first part of the experiment. Hence, we formulate the following alternative hypothesis:

Hypothesis 1b: Transfers from players $X$ to impartial decision-makers in part two are higher in the voice treatments than in the baseline only if the allocations for players $\mathrm{X}$ are favorable. If rather unfavorable outcomes are reached in part one, transfers in part two of the voice treatment are lower than in the baseline.

With the two different voice treatments, we test the effect of the extent of voice. In the narrow voice treatment, communication between player $\mathrm{X}$ and player $\mathrm{A}$ is restricted to the indication of a fair allocation. The broad voice treatment allows for a greater opportunity to express one's opinion, in that player X additionally sends a written message to player A. Based on a monotonicity argument, we expect the effect of voice (either Hypothesis 1a or 1b) to be more pronounced the more voice is granted. Hence, we predict the following:

Hypothesis 2: Voice effects are stronger in the broad voice treatment than in the narrow voice treatment.

Apart from the behavior of player $X$ towards the impartial decision-maker, we are interested in the extent to which the expectations of player $\mathrm{X}$ about the actual outcome of the allocation decision in part one are influenced by voice. In line with the instrumental motivation, research in the strategic environment of the ultimatum game suggests that voice towards the proposer increases expectations for outcomes (Ong et al., 2012; cf. Hildreth et al., 2014). If we assume that statements towards the impartial decision-maker are biased by self-interest (e.g., Babcock

11 By the same token, in principal-agent settings communication opportunities foster positive or negative reciprocal reactions towards self-interested decision-makers - depending on whether decision-makers followed the voiced suggestions (Corgnet and Hernán-González, 2013). 
and Loewenstein, 1997) and that people expect their voice to influence outcomes, we should observe the following:

Hypothesis 3: Players X expect higher outcomes from part one in the voice treatments than in the baseline.

\section{Results}

\subsection{Main Effect of Voice}

We directly turn to our main Hypotheses $1 \mathrm{a}$ and $1 \mathrm{~b}$. Therefore, we analyze the general effect of voice on transfers from players $\mathrm{X}$ to players $\mathrm{A}$ in the (unannounced) dictator game, as well as the dependence of the voice effect on the allocation chosen by player A in part 1.

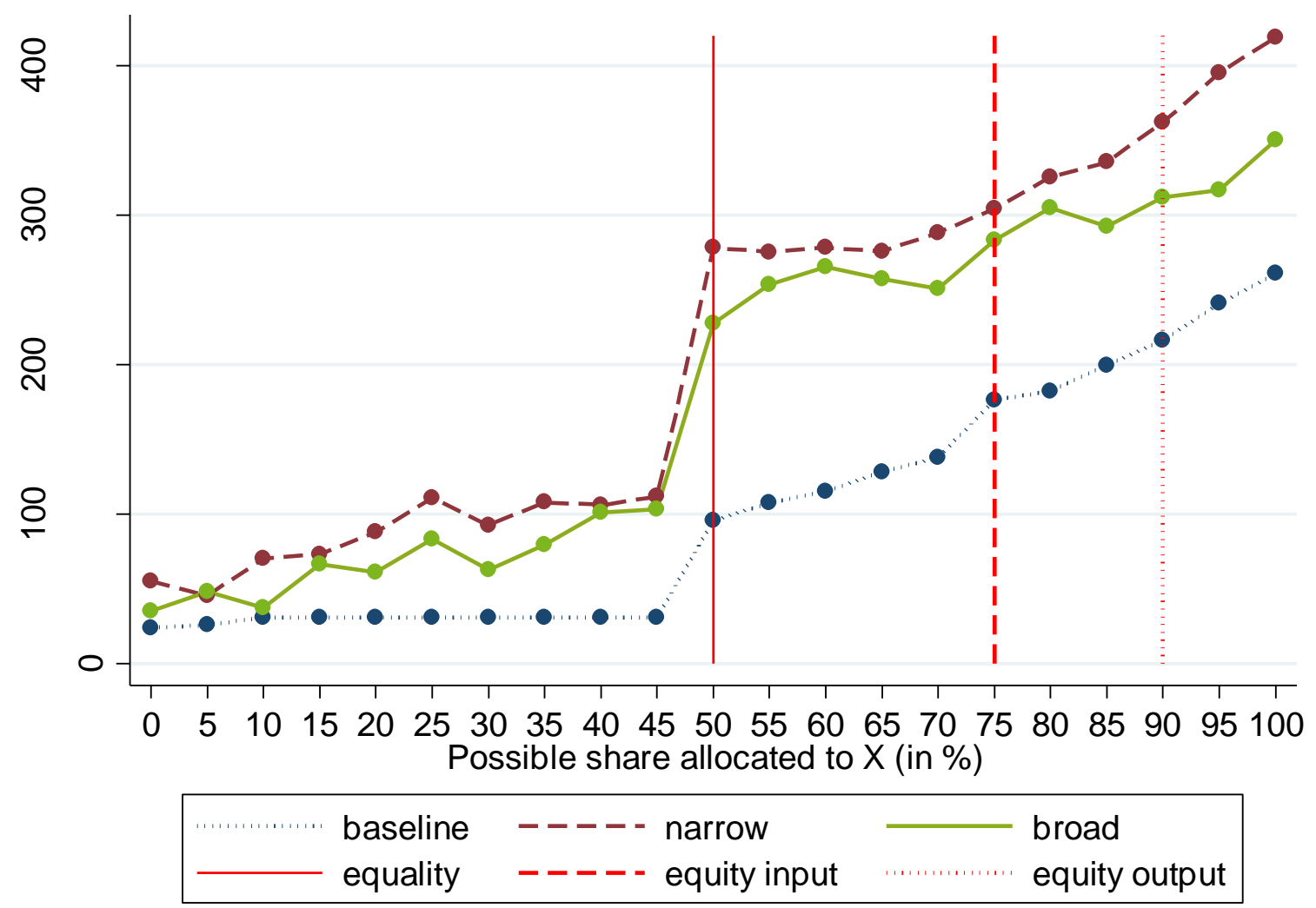

Figure 1

Mean transfers of player $\mathbf{X}$ for every possible allocation allocated to him by the impartial decision-maker

On the horizontal axis, the possible share of money allocated by players $A$ to players $X$ in part 1 of the experiment is indicated: $0 \%$ "possible share allocated to X" correspond to 0 ECU for X and $2000 \mathrm{ECU}$ for Y; $5 \%$ correspond to 100 ECU for $X$ and 1900 ECU for $Y$, etc. $100 \%$ correspond to 2000 ECU allocated to $X$ and 0 ECU to Y. The vertical lines indicate the focal normative fairness rules for allocation decisions in part 1 of the experiment. On the vertical axis, the mean transfers by players $X$ to players $A$ in part 2 of the experiment are indicated (in ECU). 
Figure 1, which shows mean transfers conditional on the possible allocations in part 1, illustrates a substantial positive effect of voice on transfers: Mean transfers are higher in both voice treatments than in the baseline. This effect is especially pronounced for all allocations which guarantee players X more than $50 \%$ of the total amount produced in the real-effort task. A sizeable jump in transfers at the equal split is present in all three treatments. This jump may be explained by the fact that allocations to players $\mathrm{X}$ below $50 \%$ of the total amount are not supported by any of the focal normative fairness rules. However, even for these "unfair" allocations to players $\mathrm{X}$, differences between the voice treatments and the baseline remain present and have the same (positive) sign as the differences in response to rather favorable allocations. Accordingly, mean transfers over all possible allocations differ largely between the voice treatments and the baseline. On average, players X transfer $210 \mathrm{ECU}(\mathrm{sd}=186)$ in the narrow voice treatment and $181 \mathrm{ECU}(\mathrm{sd}=137)$ in the broad voice treatment to the impartial decision-makers (averages over all possible allocations). Transfers are the lowest in the baseline with an average of $103 \mathrm{ECU}(\mathrm{sd}=120)$. Mann-Whitney tests show that mean transfers per player $\mathrm{X}$ are significantly higher in the voice treatments than in the baseline (narrow vs. baseline: $|\mathrm{z}|=2.390, \mathrm{p}=0.017$; broad vs. baseline: $|\mathrm{z}|=2.444, \mathrm{p}=0.015){ }^{12}$

In order to provide further evidence for the main effect of higher transfers in both voice treatments, we conduct random effects Tobit regressions, considering transfers in the dictator game as the dependent variable. ${ }^{13}$ Results are presented in Table 2.

The treatment dummies narrow and broad explain treatment differences in comparison to the baseline (level effects). In model 1, we control with possible allocation part 1 for effects that are due to a particular allocation potentially implemented by players $A$ in the first stage. In model 2, the variable fair allocation additionally controls for the private statement of players $\mathrm{X}$ about a fair allocation. ${ }^{14} \mathrm{In}$ the third model, we add the variable expectation and thereby control for the allocation expectations by players X. As male subjects are often found to make lower transfers than females in dictator games (see Engel, 2011), we control for players X' gender in model 4. The treatment effects (i.e., the dummy coefficients narrow and broad) are positive and significant in all models. This robust finding also holds if we control for further socio-economic variables. Moreover, the effect sizes of the treatment dummies are substantial, once again indicating large differences between the baseline and the voice treatments. ${ }^{15}$

12 Throughout this paper, reported p-values are always two-sided.

13 We use Tobit regressions because, in dictator games, giving possibilities are exogenously restricted with an upper and a lower bound; the lower bound is usually zero-giving. Bardsley (2008) shows that subjects also take money if they have the opportunity. In our setting, this seems plausible, since transfers show a general downward trend from favorable to unfavorable allocations to players $X$ and often stop at the zero transfer level for the most unfavorable allocations. The downward trend is therefore stopped artificially. Tobit regressions account for the possibility that (some) subjects might have even taken money instead of giving nothing by controlling for censoring. Moreover, as we have 21 transfer decisions per individual (due to the strategy method), random effects models that take individual specific effects into account are in order.

14 The private statement of a fair allocation is highly correlated with the content of the messages in both voice treatments (Spearman's Rho - narrow: $r S=0.800, p=0.000$; broad: $r S=0.754, p=0.000$ ).

15 This occurs despite the fact that according to Brandts and Charness (2011) the main limitation of the used strategy method is that it "provides a lower bound for testing for treatment effects" (p. 392). 
Hence, the regression analyses provide further support for the main effect of generally higher transfers in the voice treatments.

Table 2

Treatment effects on transfers - comparison of baseline and voice treatments

\begin{tabular}{lcccccc}
\hline \hline \multicolumn{6}{c}{ Random effects Tobit regressions (player X as group) } \\
& \multicolumn{6}{c}{ Dependent variable: transfers in the dictator game } \\
\hline & Model 1 & Model 2 & Model 3 & Model 4 & Model 5 & Model 6 \\
\hline & All Data & All Data & All Data & All Data & Females & Males \\
only
\end{tabular}

Random effects Tobit regressions. Standard errors are presented in parentheses. The narrow dummy equals 1 for all observations of the narrow voice treatment, the broad dummy equals 1 for all observations of the broad voice treatment, fair allocation controls for the allocation players X consider as fair (from $0 \mathrm{ECU}$ for $\mathrm{X}$ to 2000 ECU for X), expectation controls for players X's expectations about the actual allocation by the impartial decision-maker (from $0 \mathrm{ECU}$ for $\mathrm{X}$ to $2000 \mathrm{ECU}$ to $\mathrm{X}$ ), $\mathrm{X}$ possible allocation part 1 controls for possible allocations that can be implemented by the impartial decision-maker (from 0 ECU for $X$ to $2000 \mathrm{ECU}$ for $\mathrm{X}$ ), the male dummy equals 1 for all observations of male players $X$ Significance at the $10 \%, 5 \%$, and $1 \%$ level is denoted by *, ${ }^{* *}$, and ${ }^{* * *}$, respectively. Left-censored $=865$; right-censored $=21$ in Models $1-4$; left-censored $=364$; rightcensored $=18$ in Models 5 ; left-censored $=501$; right-censored $=3$ in Models 6 . 
Finally, we test non-parametrically if the treatment effect is robust for all possible outcomes in the first part. As indicated above, mean transfers for every possible allocation are higher in the voice treatments than in the baseline. These differences are also statistically significant for most of the possible allocations. ${ }^{16}$ Non-significant differences in transfers only emerge for extreme allocations: e.g., if players $\mathrm{X}$ receive less than $25 \%$ of the total amount. Additionally, transfers in the broad voice treatment are not significantly higher for very favorable allocations for players $X$ (when they receive $80 \%$ or more). Extreme allocations can be considered as highly unfair (for either players $\mathrm{X}$ or players $\mathrm{Y}$ ). Thus, the positive effect of voice on transfers in the dictator game is significant for all allocations, which can be supported as reasonably fair. It even persists for rather unfair allocations to player X, i.e., when player X receives less than $50 \%$ (but more than $25 \%$ ) of the total amount. In particular, in no situation are transfers lower in the voice treatments than in the baseline.

To sum up, we find strong evidence for a general positive effect of voice. Subjects' behavior is in line with Hypothesis 1a. We do not find support for a differential effect of voice on favorable versus unfavorable outcomes as hypothesized in Hypothesis $1 \mathrm{~b}$. We state the main result of our paper as follows:

Result 1: Transfers are substantially higher in both voice treatments than in the baseline. This positive effect of voice is largely independent of the previous allocation decision.

In a further explorative data analysis, we find that the treatment effects on transfers are driven by the behavior of female participants in the experiment. Male participants' mean transfers are similar in all treatments (baseline: $100 \mathrm{ECU}$, sd = 105; narrow: $107 \mathrm{ECU}, \mathrm{sd}=92$; broad: $104 \mathrm{ECU}, \mathrm{sd}=86$ ). However, female participants' mean transfers in both voice treatments are more than twice as high as in the baseline (baseline: $107 \mathrm{ECU}, \mathrm{sd}=139$; narrow: $282 \mathrm{ECU}$, sd = 203; broad: 232 ECU, sd = 143). While transfers of male participants are not statistically different between treatments (Mann-Whitney tests of mean transfers per player X: narrow vs. baseline: $|\mathrm{z}|=0.196, \mathrm{p}=0.845$; broad vs. baseline: $|\mathrm{z}|=0.294, \mathrm{p}=0.769$; see also Model 6 in Table 2), transfers of female participants are (narrow vs. baseline: $|\mathrm{z}|=2.503, \mathrm{p}=0.012$; broad vs. baseline: $|\mathrm{z}|=2.736, \mathrm{p}=0.006$; see also Model 5 in Table 2).

Result 2: The voice effect on transfers is driven by the reactions of female participants; male participants are largely unaffected by the treatments.

This finding is in line with evidence from laboratory experiments (Hack and Lammers, 2009; Dulebohn et al., 2016 for FMRI evidence) and from organizational surveys (e.g., Sweeney and McFarlin, 1997) that point towards women reacting more strongly to the fairness of procedures than men. However, other survey studies did not succeed in showing this difference (Fields et al., 2000; Lee et al., 2000; and Lee and Farh, 1999). 


\subsection{Extent of Voice}

In the following, we analyze whether the extent of voice leads to differences in transfers by comparing the two voice treatments. As Figure 1 already suggests, descriptively, differences between the voice treatments are small. Indeed, comparing the mean transfers per player $\mathrm{X}$ in the dictator game, we do not find significant differences (Mann-Whitney test, $|\mathrm{z}|=0.250, \mathrm{p}=$ 0.802). This is further supported by a Wald test, which tests whether the coefficients narrow and broad in the regression analyses presented in Table 2 are significantly different. The test exhibits no significant differences between the voice treatments ( $p>0.40$ for all models). Finally, we compare transfers in the voice treatments for every possible allocation separately. Applying the Mann-Whitney test, none of the transfer comparisons shows significant differences on conventional levels. ${ }^{17}$ Hence, we find no evidence for Hypothesis 2 :

Result 3: Transfers are not significantly different across the narrow voice and the broad voice treatment.

That absence of an effect of the extent of voice is in line with the findings of Corgnet and Hernán-González (2013). ${ }^{18}$ The numerical statement in the narrow voice treatment alone seems to be sufficient for the effect of voice.

\subsection{Expectations}

Presumably, people expect their voice to matter for the outcome of the decision (e.g., Ong et al., 2012). First we report results of the post-experimental questionnaire to elicit the perceived influence of players $X$ on the decision of players A. Players X indicate on a 11-point Likert type scale to what extent they perceive to have influenced the decision $(0=$ "no influence at all"; 10 = "very strong influence"). Not surprisingly, players $\mathrm{X}$ in the voice treatments are perceived to have a higher influence on the decision of the impartial decision-maker than those in the baseline, the differences being highly significant (Mann-Whitney test broad vs. baseline $|\mathrm{z}|=3.642, \mathrm{p}=0.000$; narrow vs. baseline $|\mathrm{z}|=3.989, \mathrm{p}=0.000) .{ }^{19}$ Moreover, the messages from players $X$ to the impartial decision-makers are highly correlated with the expected allocation (Spearman's Rho - narrow: $\mathrm{r}_{\mathrm{S}}=0.558, \mathrm{p}=0.002 ;$ broad: $\mathrm{r}_{\mathrm{S}}=0.678, \mathrm{p}=$ 0.000 ), which is another indication that the players believe their voice to matter. ${ }^{20}$ Since the baseline provides no means to players $\mathrm{X}$ to influence the decision, the perceived higher influence in the voice treatments seems obvious. Yet, it raises the question whether the perceived higher influence on the decision of players $\mathrm{A}$ also results in players $\mathrm{X}$ expecting a more favorable allocation decision in the voice treatments than in the baseline.

17 See Table A1 in the Appendix A for exact values.

18 They find similar behavior of agents who could only send a simple statement to the principal, compared to the behavior of those who could chat with the principal for three minutes. Likewise, when studying the effect of voice on the recipient of the message, Andreoni and Rao (2011) report that the numerical statement influences the recipients' behavior, but an additional written message does not. 
We now examine to what extent this is true for subjects in our experiment and turn to the analysis concerning our third hypothesis. On average, players X expect to receive $1228 \mathrm{ECU}$ ( $\mathrm{sd}=271$ ) (of the $2000 \mathrm{ECU}$ ) in the narrow voice treatment, $1230 \mathrm{ECU}$ ( $\mathrm{sd}=261$ ) in the broad voice treatment and $1334 \mathrm{ECU}(\mathrm{sd}=359)$ in the baseline (Mann-Whitney test - narrow vs. baseline $|\mathrm{z}|=1.652$, $\mathrm{p}=0.099$; broad vs. baseline $|\mathrm{z}|=1.597, \mathrm{p}=0.110$ ). Thus, despite the perceived influence on the allocation decision by players $\mathrm{A}$ in the voice treatments, players $\mathrm{X}$ do not expect higher allocations to themselves:

Result 4: Players $X$ in the voice treatments perceive that they have more influence on the decision in the allocation stage than players in the baseline. However, at the same time, they do not expect more favorable decisions.

\subsection{Earnings of Subordinates}

Using the strategy method, we show in section 4.1 that players $X$ value the voice opportunity irrespectively of outcomes. Yet, it could well be that, in the actually realized decisions, players $\mathrm{X}$ do profit from the voice procedure in monetary terms. We therefore analyze the actual earnings of players $\mathrm{X}$ in the voice treatments and in the baseline.

In total, players $\mathrm{X}$ earn significantly less in the voice treatments than in the baseline (mean earnings part 1 and 2: baseline: 2144 , sd $=291$; narrow: 1868 , sd $=378$; broad: 1893 , sd $=$ 311; Mann-Whitney test narrow vs. baseline: $|\mathrm{z}|=2.904, \mathrm{p}=0.004$; broad vs. baseline: $|\mathrm{z}|=$ 2.652, $\mathrm{p}=0.008$ ). This difference is due to two facts: First, in the voice treatments, players $\mathrm{A}$ allocate lower amounts of money to players $X$ in the first part of the experiment than in the baseline. We refer to Kleine et al. (2016) for a detailed analysis of the allocation decisions by players $\mathrm{A}$ in the first part of the experiment. Second, despite the fact that players $\mathrm{X}$ in the voice treatments receive lower amounts in the first part of the experiment, the actually realized transfers from the dictator game are significantly higher in the voice treatments than in the baseline (means: baseline: $142 \mathrm{ECU}, \mathrm{sd}=180$; narrow: $315 \mathrm{ECU}$, sd = 247; broad: 267 ECU, sd = 233; Mann-Whitney test narrow vs. baseline: $|\mathrm{z}|=2.993, \mathrm{p}=0.003$; broad vs. baseline $|\mathrm{z}|=2.378, \mathrm{p}=0.017$ ). Both aspects lead to the fact that players $\mathrm{X}$ do not profit from the voice procedures in monetary terms.

\subsection{Voice Effects on Perceived Fairness}

Although we focus on the subjects' actual behavior, we also aim at understanding whether voice shapes the subjects' perception of fairness with regard to procedures and outcomes. We again turn our analysis to players X. At the end of the experiment, players X answer questions about the perceived fairness of the procedure, namely (1) how fair they perceive the procedure to be in which the decision about the allocation came about in general, (2) how fair they perceive the procedure to be in which the decision about the allocation has been made from the viewpoint of player $\mathrm{X}$ in particular and (3) to what extent they personally feel treated fairly in 
the decision-making process. Furthermore, they are asked to state (4) the extent to which they perceive the outcome as fair and (5) the extent to which they accept the decision. All questions have to be answered on an 11-point Likert type scale ranging from $0=$ "not fair at all" to $10=$ "completely fair" $(0=$ "not at all" to $10=$ "completely" for question (5)). In line with the procedural justice literature (see for an early summary, e.g., Lind and Tyler, 1988), we predict a positive effect of voice on the perceived fairness of the procedure and of the outcomes, as well as on the acceptance of the decision.

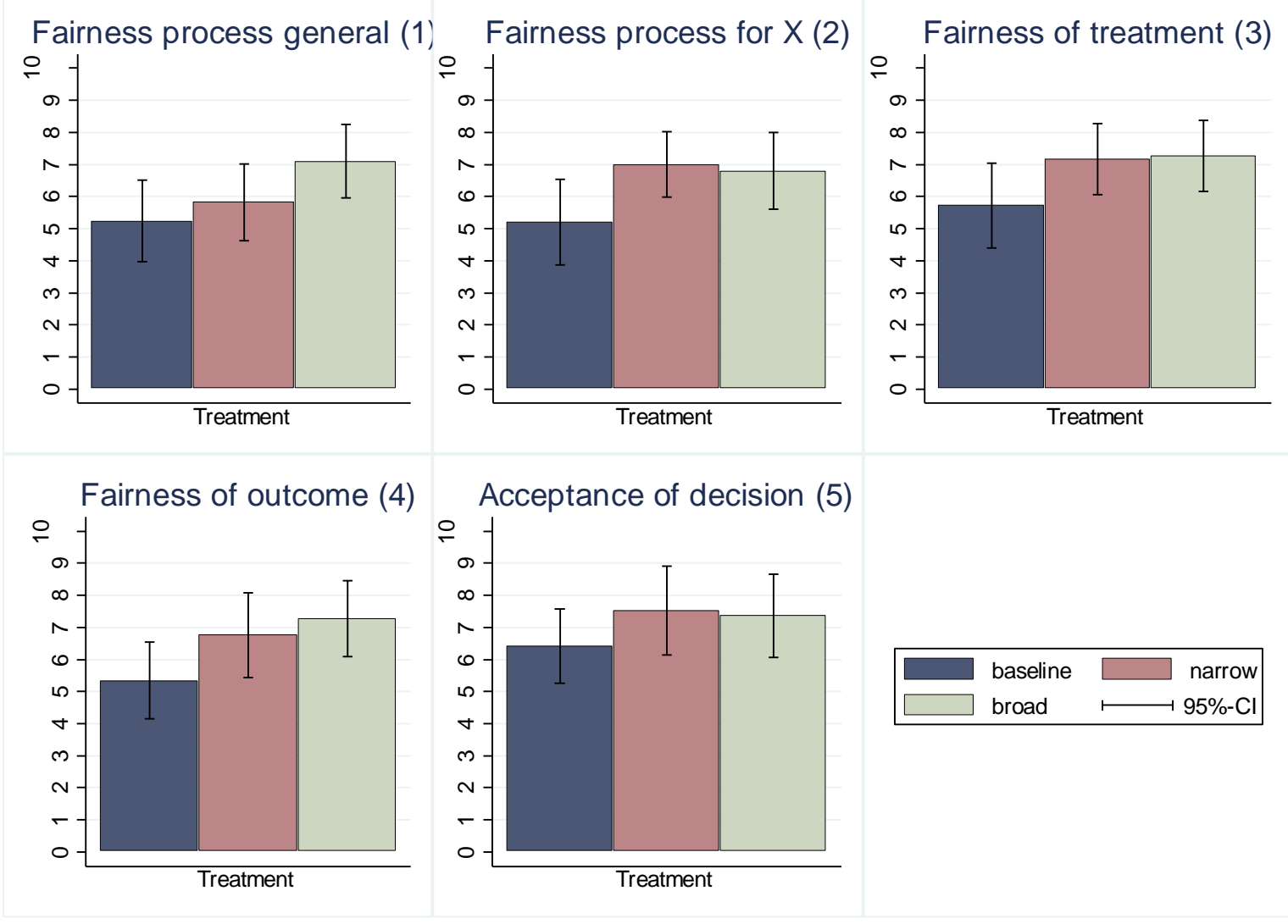

Figure 2

Players X' mean fairness ratings

The mean ratings are presented on the vertical axis. The scale goes from 0 (not at all) to 10 (completely). On the horizontal axis, one can see the different treatments. "95\%-Cl" is the $95 \%$ confidence interval. Questions asked for the overall fairness rating of the process (1), the fairness of the process from the viewpoint of player $X(2)$, the fairness of the own personal treatment (3), the fairness of the decision's outcome (4), and the extent to which players $\mathrm{X}$ can accept the decision (5).

Figure 2 illustrates the results. Indeed, the answers to the questions regarding procedural fairness, i.e., questions (1)-(3), all point in the direction that players $\mathrm{X}$ consider the voice procedure as fairer than the no-voice procedure. The results are (weakly) significant for all comparisons between the broad voice and the baseline and significant for question (2) between the 
narrow voice and the baseline. ${ }^{21}$ The higher fairness ratings in question (1) (general procedural fairness) are remarkable: In fact, the voice treatments could be considered as rather unfair in that they provide only one player with the opportunity for voice. ${ }^{22}$ Nevertheless, players $\mathrm{X}$ seem to appreciate the voice opportunity when rating procedural fairness. Furthermore, the outcomes are also judged as significantly fairer in the voice treatments than in the baseline. Finally, players $\mathrm{X}$ in the voice treatments are somewhat more willing to accept the decisions made by players A than those in the baseline. However, it has to be qualified that ratings by players $\mathrm{X}$ about the satisfaction with the outcome, indicated directly after the dictator game decisions, do not differ between treatments. Yet, overall we can conclude that from the point of view of players $\mathrm{X}$ in this setting voice increases the perceived fairness in regard to the procedure and the outcomes.

Result 5: Players $X$ in the voice treatments generally perceive the procedure and the outcomes as fairer than those in the baseline and are more willing to accept the decision by the impartial decision-makers.

\section{Extension: Voice Effect towards Uninvolved Parties?}

So far we have shown that voice has a positive effect on generous behavior towards an impartial decision-maker. Moreover, the pattern we have observed has shed some light on the underlying mechanisms of how voice affects the players who are granted voice. Yet, we make one further attempt at improving our understanding of the mechanisms behind the voice effect. Therefore, we examine the question whether voice effects can only be shown in a direct interaction with the impartial decision-maker, or whether it also affects behavior towards third, uninvolved parties. If voice effects are merely due to a positive change in the emotional state or due to an activation of a general sensibility for acting in a fair way (e.g., because participants feel treated more fairly), we conjecture that voice should also lead to more kindness towards uninvolved parties. If no such effect towards uninvolved parties occurs, this would not prove wrong the conjecture that emotional states are influenced by voice. Rather, it would favor the notion that we are correct with our interpretation that voice changes the evaluation of the impartial decision-maker (i.e., a directed expression of appreciation for being treated fairly due to voice).

Therefore, we conducted two additional treatments. In terms of design and instructions, these treatments are identical with the baseline and the narrow voice treatment described in section 2 , except that in part two the recipient of the dictator game is an uninvolved third party rather do not indicate higher fairness levels in the voice treatments (see also Table A4 in the Appendix A). 
than the impartial decision-maker. By assigning the role of the uninvolved party to a charity, ${ }^{23}$ we keep the roles in the laboratory constant. We refer to these additional treatments as baseline-uninvolved and narrow voice-uninvolved.

90 subjects participated in each of the treatments. Subjects who participated in the treatments described in section 2 of this paper were not invited to these sessions. Our analysis is based on 30 independent observations for baseline-uninvolved and 29 independent observations for narrow voice-uninvolved. One independent observation from the analysis of the narrow voice-uninvolved treatment had to be excluded from the analysis, as one subject erroneously participated in both uninvolved treatments. Participants were mainly students from various disciplines (34\% majoring in economics) with a mean age of $25.21(\mathrm{sd}=6.15) .48 \%$ were female. Participants earned 16.2 EUR on average $(\mathrm{sd}=3.3){ }^{24}$

Again, we focus on the main variable of interest - the transfers in the second part of the experiment. ${ }^{25}$ In the baseline-uninvolved treatment, players X transfer on average $184 \mathrm{ECU}$ (sd $=221$ ) to the uninvolved party (average over all possible allocations). In the narrow voiceuninvolved treatment, the mean transfer is $197 \mathrm{ECU}(\mathrm{sd}=234)$. The Mann-Whitney test that compares mean transfers is insignificant $(|z|=0.076, p=0.939)$, which confirms that mean transfers are very similar across the treatments. In addition, when we compare transfers for every possible allocation the impartial decision-maker might have implemented in the first part, we find no evidence for significant differences in transfers (for all respective MannWhitney tests: $p$ > 0.44) ${ }^{26}$ Moreover, we conduct a number of Tobit regressions (see Table A3 as an example in the Appendix A); in no model specification can we reject the null hypothesis that transfers in both treatments are the same. Also, when we analyze male and female players X separately, we find no significant treatment difference for either subgroup. We therefore state the following result:

Result 6: Transfers in the baseline-uninvolved and the narrow voice-uninvolved treatment are not statistically significantly different. In our setting, there seem to be no spillover effects of voice on behavior towards an uninvolved party.

23 The chosen charity, "Deutsche Welthungerhilfe e.V.", supports development projects against hunger and poverty worldwide. Subjects were informed about the goal of the charity and that it is certified by the "Stiftung Deutsches Zentralinstitut für soziale Fragen" (German Central Institute for Social Issues). 16.2 EUR corresponded to around 21.1 USD at the time of the experiment. The earnings include a showup fee of 4 EUR and a payment of 2 Euros for answering the questionnaire.

25 Since we implemented the uninvolved treatments to test whether voice also affects the subordinate's behavior towards an uninvolved party, we limit our analysis to the transfers of players X. For results on the other variables (expectations, perceived fairness ratings), we refer to the Table A5 in the Appendix A. It has to be noted that comparisons of non-incentivized perceived fairness ratings across these treatments do not yield the same results as those in the main experiment. Applying Mann-Whitney tests, all comparisons between baseline-uninvolved and narrow voice-uninvolved are insignificant. This indicates that the fairness ratings are to some extent influenced by the overall setting in which players make their decisions. See Table A2 in the Appendix A for exact values. 


\section{Conclusion}

Our experimental study provides evidence on how people's post-decision behavior is affected by their pre-decision opportunity for voice in an incentivized decision environment. We show that voice in decision procedures increases subordinates' kindness towards an impartial decision-maker. The effect seems to be largely independent of the outcomes subordinates receive: Participants value the opportunity to state their opinion in the decision-making process even when outcomes turn out unfavorable. In that sense, our results for interactions with an impartial decision-maker are distinct from the behavioral effects of voice towards a self-interested decision-maker (Corgnet and Hernán-Gonzalez, 2013; Ong et al., 2012). Note that our experiment is not meant to directly test instrumental vs. non-instrumental effects of voice against each other. Yet, the results are consistent with a non-instrumental function or a "mild" instrumental function of having voice, as we observe no reversed (negative) voice effect for unfair decisions. The observed patterns are inconsistent with the prediction that voice only has positive effects when it leads to favorable outcomes.

Our results further indicate that participation opportunities do not need to be extensive, since there are no differences between the two voice treatments and since restricted voice already substantially improves the relationship between the decision-maker and the subordinate. Yet, the analysis of gender differences further suggests that the observed strong voice effects are mainly due to women's reactions to having voice; men do not seem to be affected. Further, surprisingly, voice towards an impartial decision-maker does not increase the subordinates' expectations of favorable outcomes.

Of course, important questions remain. In our setting, only one out of two subordinates has the voice opportunity. This restriction allows us to identify the pure effect of voice. Nonetheless, it would be interesting to test if and how the effect changes if - as, for example, in court - more than one subordinate may express herself. A further important question is how voice affects behavior towards a more powerful decision-maker who can also decide about the decision-making process, i.e., who can grant or deny voice opportunities at her discretion. Lastly, the gender differences in our data are remarkable. We had no ex-ante hypothesis on such gender differences and therefore decided to refrain from an in depth analysis and interpretation. Nevertheless, we think that it might be interesting for future research to explore the robustness of this finding and possible explanations for it. Along these lines, more experimental evidence is needed to understand the importance of voice procedures in social interactions. Our experimental design may serve as a general framework to address these questions.

\section{Acknowledgments}

We are grateful for comments by Christoph Engel, Susann Fiedler, and Nikos Nikiforakis on an earlier version. We would also like to thank On Amir, Gary Charness, Uri Gneezy, Sebastian J. Goerg, Joel Sobel, and Erte Xiao for insightful discussions. The paper benefited from 
comments made at the Economic Science Association Conferences in Cologne, Tucson and Zurich, the Conference of the Italian Society of Law and Economics in Rome, the International Meeting on Behavioral and Experimental Economics in Madrid, the Workshop on Behavioral and Experimental Economics in Florence, the Maastricht Behavioral and Experimental Economics Symposium, the Tiber Symposium on Psychology and Economics in Tilburg, and the Conference on Empirical Legal Studies in Philadelphia. We gratefully acknowledge financial support from the Max Planck Institute for Research on Collective Goods. 


\section{References}

Abeler, J., Falk, A., Goette, L., \& Huffman, D. (2011). Reference points and effort provision. The American Economic Review, 101(2), 470-492.

Andreoni, J., \& Rao, J. M. (2011). The power of asking: How communication affects selfishness, empathy, and altruism. Journal of Public Economics, 95(7-8), 513-520.

Babcock, L., \& Loewenstein, G. (1997). Explaining bargaining impasse: The role of selfserving biases. The Journal of Economic Perspectives, 11(1), 109-126.

Bardsley, N. (2008). Dictator game giving. Altruism or artefact? Experimental Economics, $11(2), 122-133$.

Bolton, G. E., Brandts, J., \& Ockenfels. A. (2005). Fair procedures: Evidence from games involving lotteries. The Economic Journal, 115(506), 1054-1076.

Brandts, J., \& Charness, G. (2003). Truth or consequences: An experiment. Management Science, 49(1), 116-130.

Brandts, J., \& Charness, G. (2011). The strategy versus the direct-response method: A first survey of experimental comparisons. Experimental Economics, 14(3), 375-398.

Charness, G., Cobo-Reyes, R., Jiménez, N., Lacomba, J. A., \& Lagos, F. (2012). The hidden advantage of delegation: Pareto improvements in a gift exchange game. The American Economic Review, 102(5), 2358-2379.

Charness, G., \& Rabin, M. (2005). Expressed preferences and behavior in experimental games. Games and Economic Behavior, 53(2), 151-169.

Corgnet, B., \& Hernán-González, R. (2013). Don’t ask me if you will not listen: The dilemma of consultative participation. Management Science, 60(3), 560-585.

Dal Bó, P., Foster, A., \& Putterman, L. (2010). Institutions and behavior: Experimental evidence on the effects of democracy. The American Economic Review, 100(5), 22052229.

Dold, M., \& Khadjavi, M. (2016). Jumping the queue: An experiment on procedural preferences. Games and Economic Behavior, forthcoming.

Dulebohn, J. H., Davison, R. B., Lee, S. A., Conlon, D. E., McNamara, G., \& Sarinopoulos, I. C. (2016). Gender differences in justice evaluations: Evidence from fMRI. Journal of Applied Psychology, 101(2), 151-170.

Engel, C. (2011). Dictator games: A meta study. Experimental Economics, 14(4), 583-610. 
Falk, A., \& Kosfeld, M. (2006). The hidden costs of control. The American Economic Review, 96(5), 1611-1630.

Fields, D., Pang, M., \& Chiu, C. (2000). A comparative field study of the effects of distributive and procedural justice in Hong Kong. Journal of Organizational Behavior, 21(5), 547-562.

Fischbacher, U. (2007). z-Tree: Zurich toolbox for ready-made economic experiments. Experimental Economics, 10(2), 171-178.

Folger, R. (1977). Distributive and procedural justice: Combined impact of voice and improvement on experienced inequity. Journal of Personality and Social Psychology, $35(2), 108-119$.

Folger, R., Rosenfield, D., Grove, J., \& Corkran, L. (1979). Effects of "voice" and peer opinions on responses to inequity. Journal of Personality and Social Psychology, 37(12), 2253-2261.

Forsythe R., Horowitz, J. L., Savin, N. E., \& Sefton, M. (1994). Fairness in simple bargaining experiments. Games and Economic Behavior, 6(3), 347-369.

Frey, B. S., Kucher, M., \& Stutzer, A. (2001). Outcome, process and power in direct democracy. New econometric results. Public Choice, 107(3), 271-293.

Frey, B. S., \& Stutzer, A. (2005). Beyond outcomes - Measuring procedural utility. Oxford Economic Papers, 57(1), 90-111.

Frey, B. S., Benz, M., \& Stutzer, A. (2004). Introducing procedural utility: Not only what, but also how matters. Journal of Institutional and Theoretical Economics, 160(3), 377-401.

Greiner, B. (2015). Subject pool recruitment procedures: Organizing experiments with ORSEE. Journal of the Economic Science Association, 1(1), 114-125.

Hack, A., \& Lammers, F. (2009). Gender as a moderator of the fair process effect. Social Psychology, 40(4), 202-211.

Hildreth J. A. D., Moore, D. A., \& Blader, S. L. (2014). Revisiting the instrumentality of voice: Having voice in the process makes people think they will get what they want. Social Justice Research, 27(2), 209-230.

Hirschman, A. O. (1970). Exit, voice and loyalty: Responses to decline in firms, organizations, and states. Cambridge, MA: Harvard University Press.

Kleine, M., Langenbach, P., \& Zhurakhovska, L. (2016). Fairness and persuasion: How stakeholder communication affects impartial decision making. Economics Letters, 141, 173-176. 
Köhler, K., Pagel, B., \& Rau, H. A. (2015). How worker participation affects reciprocity under minimum remuneration policies: Experimental evidence. Discussion Papers, Center for European Governance and Economic Development Research No. 267.

Konow, J. (2000). Fair shares: Accountability and cognitive dissonance in allocation decisions. The American Economic Review, 90(4), 1072-1091.

Ku, H., \& Salmon, T. C. (2013). Procedural fairness and the tolerance for income inequality. European Economic Review, 64, 111-128.

Lee, C., \& Farh, J. L. (1999). The effects of gender in organizational justice perception. Journal of Organizational Behavior, 20(1), 133-143.

Lee, C., Pillutla, M., \& Law, K. S. (2000). Power-distance, gender and organizational justice. Journal of Management, 26(4), 685-704.

Lind, E. A., Kanfer, R., \& Earley, P. C. (1990). Voice, control, and procedural justice: Instrumental and noninstrumental concerns in fairness judgments. Journal of Personality and Social Psychology, 59(5), 952-959.

Lind, E. A., \& Tyler, T. R. (1988). The social psychology of procedural justice. New York: Plenum Press.

Markussen, T., Putterman, L., \& Tyran, J. R. (2014). Self-organization for collective action: An experimental study of voting on sanction regimes. Review of Economic Studies, 81(1), 301-324.

McClintock, C. G., \& Liebrand, W. B. (1988). Role of interdependence structure, individual value orientation, and another's strategy in social decision making: A transformational analysis. Journal of Personality and Social Psychology, 55(3), 396-409.

Mohlin, E., \& Johannesson, M. (2008). Communication: Content or relationship? Journal of Economic Behavior \& Organization, 65(3-4), 409-419.

Nikiforakis, N., Noussair, C. N., \& Wilkening, T. (2012). Normative conflict and feuds: The limits of self-enforcement. Journal of Public Economics, 96(9-10), 797-807.

Ong, Q., Riyanto, Y. E., \& Sheffrin, S. M. (2012). How does voice matter? Evidence from the ultimatum game. Experimental Economics, 15(4), 604-621.

Ong, Q., Riyanto, Y. E., Theseira, W. E., \& Sheffrin, S. M. (2013). The self-image signaling roles of voice in decision-making. Nanyang Technological University, Economic Growth Centre Working Paper Series No. 1303.

Rankin, F. W. (2003). Communication in ultimatum games. Economics Letters, 81(2), 267271. 
Rankin, F. W. (2006). Request and social distance in dictator games. Journal of Economic Behavior \& Organization, 60(1), 27-36.

Reuben, E., \& Riedl, A. (2013). Enforcement of contribution norms in public good games with heterogeneous populations. Games and Economic Behavior, 77(1), 122-137.

Selten, R. (1967). Die Strategiemethode zur Erforschung des eingeschränkt rationalen Verhaltens im Rahmen eines Oligopolexperiments. In H. Sauermann (Ed.), Beiträge zur experimentellen Wirtschaftsforschung (pp. 136-168). Mohr: Tübingen.

Shapiro, D. L. (2001). The death of justice theory is likely if theorists neglect the "wheels" already invented and the voices of the injustice victims. Journal of Vocational Behavior, $58(2), 235-242$.

Shapiro, D. L., \& Brett, J. M. (1993). Comparing three processes underlying judgments of procedural justice: A field study of mediation and arbitration. Journal of Personality and Social Psychology, 65(6), 1167-1177.

Sweeney, P. D., \& McFarlin, D. B. (1997). Process and outcome: Gender differences in the assessment of justice. Journal of Organizational Behavior, 18(1), 83-98.

Thibaut, J., \& Walker, L. (1975). Procedural justice: A psychological analysis. Hillsdale, NJ: L. Erlbaum Associates.

Thibaut, J., \& Walker, L. (1978). A theory of procedure. California Law Review, 66(3), 541566.

Trautmann, S. (2009). A tractable model of process fairness under risk. Journal of Economic Psychology, 30(5), 803-813.

Tyler, T. R. (2006). Why people obey the law. Princeton, NJ: Princeton University Press.

Tyler, T. R., Rasinski, K. A., \& Spodick, N. (1985). Influence of voice on satisfaction with leaders: Exploring the meaning of process control. Journal of Personality and Social Psychology, 48(1), 72-81.

Tyran, J. R., \& Feld, L. P. (2006). Achieving compliance when legal sanctions are nondeterrent. The Scandinavian Journal of Economics, 108(1), 135-156.

Xiao, E., \& Houser, D. (2005). Emotion expression in human punishment behavior. Proceedings of the National Academy of Sciences, 102(20), 7398-7401.

Yamamori, T., Kato, K., Kawagoe, T., \& Matsui, A. (2008). Voice matters in a dictator game. Experimental Economics, 11(4), 336-343. 


\section{Appendix A. Tables}

Table A1

Pairwise treatment comparison of transfers in the dictator game conditional on every possible allocation

\begin{tabular}{|c|c|c|c|c|}
\hline \multicolumn{5}{|c|}{ Mann-Whitney tests: p-values, $|z|$ in parentheses } \\
\hline \multicolumn{2}{|c|}{ Possible allocation } & \multirow{2}{*}{$\begin{array}{c}\text { baseline vs. nar- } \\
\text { row }\end{array}$} & \multirow{2}{*}{$\begin{array}{c}\text { baseline vs. broad } \\
0.543,(0.608)\end{array}$} & \multirow{2}{*}{$\frac{\text { narrow vs. broad }}{0.353,(0.929)}$} \\
\hline$X: 2000$ & $Y: 0$ & & & \\
\hline$X: 1900$ & $Y: 100$ & $0.037,(2.081)$ & $0.477,(0.712)$ & $0.234,(1.190)$ \\
\hline$X: 1800$ & Y: 200 & $0.031,(2.156)$ & $0.219,(1.229)$ & $0.424,(0.800)$ \\
\hline$X: 1700$ & Y: 300 & $0.034,(2.120)$ & $0.138,(1.483)$ & $0.522,(0.640)$ \\
\hline$X: 1600$ & $Y: 400$ & $0.034,(2.123)$ & $0.050,(1.959)$ & $0.772,(0.290)$ \\
\hline$X: 1500$ & $Y: 500$ & $0.048,(1.974)$ & $0.075,(1.779)$ & $0.691,(0.397)$ \\
\hline$X: 1400$ & $Y: 600$ & $0.029,(2.185)$ & $0.030,(2.168)$ & $0.725,(0.351)$ \\
\hline$X: 1300$ & Y: 700 & $0.028,(2.191)$ & $0.013,(2.484)$ & $0.957,(0.054)$ \\
\hline$X: 1200$ & $Y: 800$ & $0.011,(2.549)$ & $0.006,(2.753)$ & $0.939,(0.077)$ \\
\hline$X: 1100$ & Y: 900 & $0.011,(2.549)$ & $0.013,(2.475)$ & $0.753,(0.315)$ \\
\hline$X: 1000$ & $Y: 1000$ & $0.002,(3.080)$ & $0.010,(2.590)$ & $0.442,(0.769)$ \\
\hline$X: 900$ & $Y: 1100$ & 0.057, (1.906) & $0.013,(2.476)$ & $0.655,(0.447)$ \\
\hline$X: 800$ & Y: 1200 & $0.059,(1.887)$ & $0.014,(2.458)$ & $0.673,(0.422)$ \\
\hline$X: 700$ & $Y: 1300$ & $0.059,(1.887)$ & $0.018,(2.376)$ & $0.807,(0.245)$ \\
\hline$X: 600$ & Y: 1400 & $0.066,(1.838)$ & $0.055,(1.916)$ & $0.931,(0.086)$ \\
\hline$X: 500$ & $Y: 1500$ & $0.059,(1.887)$ & $0.088,(1.705)$ & $0.787,(0.271)$ \\
\hline$X: 400$ & $Y: 1600$ & $0.113,(1.587)$ & $0.153,(1.428)$ & $0.822,(0.225)$ \\
\hline X: 300 & Y: 1700 & $0.127,(1.526)$ & $0.230,(1.199)$ & $0.722,(0.356)$ \\
\hline$X: 200$ & Y: 1800 & $0.137,(1.486)$ & $0.255,(1.139)$ & $0.681,(0.411)$ \\
\hline$X: 100$ & $Y: 1900$ & $0.221,(1.223)$ & 0.363, (0.909) & $0.776,(0.284)$ \\
\hline$X: 0$ & $Y: 2000$ & $0.693,(0.395)$ & $0.780,(0.279)$ & $0.898,(0.128)$ \\
\hline
\end{tabular}


Table A2

Pairwise treatment comparison of transfers in the dictator game conditional on every possible allocation - uninvolved treatments

Mann-Whitney tests: $p$-values, $|z|$ in parentheses

\begin{tabular}{|c|c|c|}
\hline \multicolumn{2}{|c|}{ Possible allocation } & $\begin{array}{c}\text { Baseline-uninvolved vs. Narrow voice- } \\
\text { uninvolved }\end{array}$ \\
\hline$X: 2000$ & $Y: 0$ & $0.725,(0.351)$ \\
\hline$X: 1900$ & Y: 100 & $0.527,(0.633)$ \\
\hline$X: 1800$ & $Y: 200$ & $0.557,(0.588)$ \\
\hline$X: 1700$ & $Y: 300$ & $0.537,(0.618)$ \\
\hline$X: 1600$ & $Y: 400$ & $0.562,(0.580)$ \\
\hline$X: 1500$ & $Y: 500$ & $0.737,(0.336)$ \\
\hline$X: 1400$ & $Y: 600$ & $0.909,(0.115)$ \\
\hline$X: 1300$ & Y: 700 & $0.836,(0.207)$ \\
\hline$X: 1200$ & $Y: 800$ & $0.830,(0.214)$ \\
\hline$X: 1100$ & $Y: 900$ & $0.812,(0.237)$ \\
\hline$X: 1000$ & $Y: 1000$ & $0.853,(0.185)$ \\
\hline$X: 900$ & $Y: 1100$ & $0.733,(0.341)$ \\
\hline$X: 800$ & $Y: 1200$ & $0.640,(0.468)$ \\
\hline $\mathrm{X}: 700$ & $Y: 1300$ & $0.564,(0.577)$ \\
\hline$X: 600$ & $Y: 1400$ & $0.994,(0.008)$ \\
\hline$X: 500$ & $Y: 1500$ & $0.795,(0.260)$ \\
\hline$X: 400$ & $Y: 1600$ & $0.961,(0.049)$ \\
\hline$X: 300$ & Y: 1700 & $0.915,(0.107)$ \\
\hline$X: 200$ & $Y: 1800$ & $0.935,(0.082)$ \\
\hline$X: 100$ & $Y: 1900$ & $0.582,(0.551)$ \\
\hline $\mathrm{X}: 0$ & $Y: 2000$ & $0.443,(0.768)$ \\
\hline
\end{tabular}


Table A3

Treatment effects on transfers - comparison of baseline-uninvolved and narrow voiceuninvolved

Random effects Tobit regressions (player $\mathrm{X}$ as group)

Dependent variable: transfers in the dictator game

\begin{tabular}{lcccccc}
\hline & Model 1 & Model 2 & Model 3 & Model 4 & Model 5 & Model 6 \\
\hline & All Data & All Data & All Data & All Data & $\begin{array}{c}\text { Females } \\
\text { only }\end{array}$ & $\begin{array}{c}\text { Males } \\
\text { only }\end{array}$ \\
\hline Narrow voice- & 22.56 & 41.65 & 74.68 & 81.64 & 74.73 & 69.71 \\
uninvolved & $(111.82)$ & $(106.62)$ & $(103.73)$ & $(100.15)$ & $(126.88)$ & $(162.13)$ \\
Fair allocation & & $-0.36^{* *}$ & 0.02 & .03 & .22 & .08 \\
& & $(0.18)$ & $(0.25)$ & $(.24)$ & $(.40)$ & $(.34)$ \\
Expectation & & & $-0.53^{* *}$ & $-.55^{* *}$ & $-.83^{* *}$ & -.18 \\
& & & $(0.25)$ & $(.24)$ & $(.38)$ & $(.38)$ \\
Male & & & & $-181.92^{*}$ & & \\
& & & & $(98.95)$ & & \\
Possible alloca- & $0.22^{* * *}$ & $0.22^{\star * *}$ & $0.22^{* * *}$ & $.22^{\star * *}$ & $.13^{* \star *}$ & $.37^{* * *}$ \\
tion part 1 & $(0.01)$ & $(0.01)$ & $(0.01)$ & $(.01)$ & $(.01)$ & $(.02)$ \\
Constant & $-174.91^{* *}$ & 335.22 & $448.71^{*}$ & $553.69^{* *}$ & $751.58^{* * *}$ & -339.79 \\
& $(79.43)$ & $(259.31)$ & $(254.55)$ & $(252.42)$ & $(279.51)$ & $(496.86)$ \\
\hline $\mathrm{N}$ & 1239 & 1239 & 1239 & 1239 & 651 & 588 \\
$\mathrm{~N}$ of groups & 59 & 59 & 59 & 59 & 31 & 28 \\
$\mathrm{P}$ model & $<.000$ & $<.000$ & $<.000$ & $<.000$ & $<.000$ & $<.000$ \\
Wald Chi2 & 513.11 & 516.63 & 520.02 & 522.69 & 187.75 & 358.55 \\
\hline
\end{tabular}

Random effects Tobit regression. Standard errors are presented in parentheses. The narrow voice-uninvolved dummy equals 1 for all observations of the narrow voice-uninvolved treatment, fair allocation controls for the differences in the allocation players X consider as fair (from 0 ECU for X to 2000 ECU for X), expectation controls for the differences in players $X$ 's expectation about the actual allocation by the impartial decision-makers (from 0 ECU for X to 2000 ECU for X), possible allocation part 1 controls for possible allocations that can be implemented by the impartial decision-makers (from 0 ECU for $X$ to 2000 ECU for $X$ ), the male dummy equals 1 for all observations of male players X. Significance at the $10 \%, 5 \%$ and $1 \%$ level is denoted by * ${ }^{* *}$ and ${ }^{* * *}$, respectively. Left-censored $=432$; right-censored $=68$ in Models 1-4; left-censored $=169$; right-censored $=32$ in Models 5; left-censored $=263$; right-censored $=36$ in Models 6 . 
Table A4

Expectations and perceived fairness in baseline- and voice treatments

\begin{tabular}{|c|c|c|c|c|c|c|}
\hline & & baseline & narrow & broad & $\begin{array}{c}\text { Mann- } \\
\text { Whitney } \\
\text { tests } \\
\text { baseline } \\
\text { vs. narrow }\end{array}$ & $\begin{array}{c}\text { Mann- } \\
\text { Whitney } \\
\text { tests } \\
\text { baseline } \\
\text { vs. } \\
\text { broad }\end{array}$ \\
\hline & & $\begin{array}{l}\text { Mean } \\
\text { (sd) }\end{array}$ & $\begin{array}{l}\text { Mean } \\
\text { (sd) }\end{array}$ & $\begin{array}{c}\text { Mean } \\
\text { (sd) }\end{array}$ & $\begin{array}{c}p \text {-values } \\
(|z|)\end{array}$ & $\begin{array}{c}\text { p-values } \\
(|z|)\end{array}$ \\
\hline \multirow{2}{*}{ 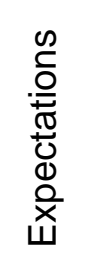 } & Perceived influence by players $X$ & $\begin{array}{l}1.90 \\
(2.55)\end{array}$ & $\begin{array}{c}5.55 \\
(3.56)\end{array}$ & $\begin{array}{c}4.97 \\
(3.19)\end{array}$ & $\begin{array}{c}0.000 \\
(3.989)\end{array}$ & $\begin{array}{c}0.000 \\
(3.642)\end{array}$ \\
\hline & $\begin{array}{l}\text { Expectation of players } X \text { con- } \\
\text { cerning allocation in part } 1\end{array}$ & $\begin{array}{l}1334 \\
(359)\end{array}$ & $\begin{array}{l}1228 \\
(271)\end{array}$ & $\begin{array}{l}1230 \\
(261)\end{array}$ & $\begin{array}{c}0.099 \\
(1.652)\end{array}$ & $\begin{array}{c}0.110 \\
(1.597)\end{array}$ \\
\hline \multirow{6}{*}{ 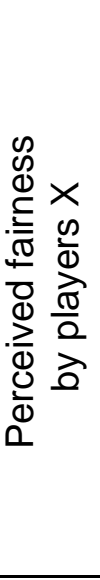 } & Fairness process general (1) & $\begin{array}{c}5.24 \\
(3.31)\end{array}$ & $\begin{array}{c}5.83 \\
(3.14)\end{array}$ & $\begin{array}{c}7.10 \\
(3.06)\end{array}$ & $\begin{array}{c}0.495 \\
(0.682)\end{array}$ & $\begin{array}{c}0.025 \\
(2.241)\end{array}$ \\
\hline & Fairness process for $\mathrm{X}(2)$ & $\begin{array}{c}5.21 \\
(3.50)\end{array}$ & $\begin{array}{c}7.00 \\
(2.69)\end{array}$ & $\begin{array}{c}6.80 \\
(3.18)\end{array}$ & $\begin{array}{c}0.050 \\
(1.957)\end{array}$ & $\begin{array}{c}0.075 \\
(1.781)\end{array}$ \\
\hline & Fairness of treatment (3) & $\begin{array}{c}5.72 \\
(3.45)\end{array}$ & $\begin{array}{c}7.17 \\
(3.49)\end{array}$ & $\begin{array}{c}7.27 \\
(2.98)\end{array}$ & $\begin{array}{c}0.127 \\
(1.527)\end{array}$ & $\begin{array}{c}0.092 \\
(1.685)\end{array}$ \\
\hline & Fairness of outcome (4) & $\begin{array}{c}5.34 \\
(3.12)\end{array}$ & $\begin{array}{c}6.76 \\
(3.49)\end{array}$ & $\begin{array}{c}7.27 \\
(3.15)\end{array}$ & $\begin{array}{c}0.064 \\
(1.853)\end{array}$ & $\begin{array}{c}0.014 \\
(2.467)\end{array}$ \\
\hline & Acceptance of decision (5) & $\begin{array}{c}6.41 \\
(3.04)\end{array}$ & $\begin{array}{c}7.52 \\
(3.62)\end{array}$ & $\begin{array}{c}7.37 \\
(3.48)\end{array}$ & $\begin{array}{c}0.044 \\
(2.013)\end{array}$ & $\begin{array}{c}0.107 \\
(1.610)\end{array}$ \\
\hline & Fairness process for $Y$ & $\begin{array}{c}4.52 \\
(3.38) \\
\end{array}$ & $\begin{array}{c}4.93 \\
(3.29) \\
\end{array}$ & $\begin{array}{c}5.30 \\
(3.43) \\
\end{array}$ & $\begin{array}{c}0.606 \\
(0.516) \\
\end{array}$ & $\begin{array}{c}0.325 \\
(0.984) \\
\end{array}$ \\
\hline
\end{tabular}

Perceived influence as well as all perceived fairness ratings on a Likert type scale from 0 ("not at all") to 10 ("completely"); expectation in ECU. 
Table A5

Expectations and perceived fairness in baseline-uninvolved and narrow voice-uninvolved

\begin{tabular}{|c|c|c|c|c|}
\hline & & $\begin{array}{l}\text { baseline- } \\
\text { uninvolved }\end{array}$ & $\begin{array}{l}\text { narrow- } \\
\text { uninvolved }\end{array}$ & $\begin{array}{l}\text { Mann-Whitney tests } \\
\text { baseline-uninvolved } \\
\text { vs. narrow voice- } \\
\text { uninvolved }\end{array}$ \\
\hline & & $\begin{array}{l}\text { Mean } \\
\text { (sd) }\end{array}$ & $\begin{array}{l}\text { Mean } \\
(\mathrm{sd})\end{array}$ & $\begin{array}{c}p \text {-values } \\
(|z|)\end{array}$ \\
\hline \multirow{2}{*}{ 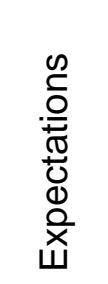 } & Perceived influence by players $X$ & $\begin{array}{c}1.27 \\
(2.53)\end{array}$ & $\begin{array}{c}4.28 \\
(3.52)\end{array}$ & $\begin{array}{c}0.000 \\
(3.640)\end{array}$ \\
\hline & $\begin{array}{c}\text { Expectation of players } \mathrm{X} \text { concern- } \\
\text { ing allocation in part } 1\end{array}$ & $\begin{array}{l}1223 \\
(310)\end{array}$ & $\begin{array}{l}1341 \\
(298)\end{array}$ & $\begin{array}{c}0.117 \\
(1.568)\end{array}$ \\
\hline \multirow{6}{*}{ 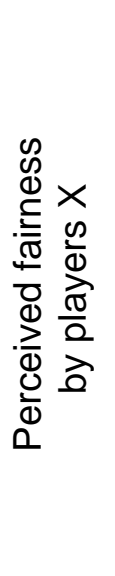 } & Fairness process general (1) & $\begin{array}{c}6.47 \\
(2.98)\end{array}$ & $\begin{array}{c}5.62 \\
(3.19)\end{array}$ & $\begin{array}{l}0.317 \\
(1.00)\end{array}$ \\
\hline & Fairness process for $\mathrm{X}(2)$ & $\begin{array}{l}6.63 \\
(2.89)\end{array}$ & $\begin{array}{c}6.07 \\
(3.67)\end{array}$ & $\begin{array}{c}0.730 \\
(0.345)\end{array}$ \\
\hline & Fairness of treatment (3) & $\begin{array}{l}5.90 \\
(3.26)\end{array}$ & $\begin{array}{c}6.45 \\
(3.77)\end{array}$ & $\begin{array}{c}0.377 \\
(0.883)\end{array}$ \\
\hline & Fairness of outcome (4) & $\begin{array}{l}6.60 \\
(3.40)\end{array}$ & $\begin{array}{c}6.00 \\
(3.99)\end{array}$ & $\begin{array}{c}0.468 \\
(0.727)\end{array}$ \\
\hline & Acceptance of decision (5) & $\begin{array}{l}7.30 \\
(3.37)\end{array}$ & $\begin{array}{c}6.72 \\
(4.01)\end{array}$ & $\begin{array}{c}0.585 \\
(0.546)\end{array}$ \\
\hline & Fairness process for $Y$ & $\begin{array}{c}6.00 \\
(3.01)\end{array}$ & $\begin{array}{l}6.07 \\
(2.91)\end{array}$ & $\begin{array}{c}0.982 \\
(0.023)\end{array}$ \\
\hline
\end{tabular}

Perceived influence as well as all perceived fairness ratings on a Likert type scale from 0 ("not at all") to 10 ("completely"); expectation in ECU. 


\section{Appendix B. Instructions}

The instructions for the baseline and the voice treatments only differ in one regard. In the first experiment, the baseline consists only of Steps 1 and 2. In the voice treatments, an additional intermediate Step between these two is introduced. Therefore, we report first the full instructions of the baseline and afterwards only the new Step 2 of the voice treatments. Instructions have been translated into English. The social value orientation test was introduced as a second experiment.

\section{B.1 Instructions Baseline}

\section{General Instructions for Participants}

Please begin by reading these instructions carefully. Communication during the experiments is prohibited. If you have any questions, please raise your hand. We will then come to you. Disobeying this rule will lead to exclusion from the experiment and all payments.

The experiments are conducted anonymously, i.e., nobody is told with which other participant he or she has interacted. The analysis of the experiment results will also be conducted anonymously.

You will take part in several experiments today. You can earn money during the experiments, depending on the decisions you and the other participants make. In the first experiment, we speak not of $€$, but of Taler. Your income from this experiment is therefore initially calculated in Taler. At the end of the experiment, the Taler earned are converted into Euro at a rate of 2 Taler $=1$ Cent and paid out to you. In addition, each participant receives a lump sum payment of 4 Euro for showing up today.

The instructions for the individual experiments will be handed out to you just before each respective experiment. On the following pages, we will first describe the exact procedure of the first experiment. Then, there will be more experiments. It will be impossible for you to lose your earnings from one of the experiments in a later experiment.

After the final experiment, you will be given a questionnaire. Once you have filled in this questionnaire, the total sum you have earned will be paid to you in cash. 


\section{Information on the First Experiment: Part 1}

In this experiment, there are three roles: $\mathbf{A}, \mathbf{X}$, and $\mathbf{Y}$. At the beginning of the experiment, you are assigned a role at random. One participant $\mathrm{A}$, one participant $\mathrm{X}$, and one participant $\mathrm{Y}$ form a group in this experiment. In this part of the experiment, participant $\mathbf{A}$ receives a fixed lump sum of 5 Euro, which remains unaltered regardless of the decisions taken by $A$ or the other participants. The earnings of participants $\mathbf{X}$ and $\mathbf{Y}$ are determined by the decisions made in the course of the experiment. We shall now explain how exactly this works.

This experiment consists of several parts. First, we explain and conduct the first part of the experiment. You will receive further information separately for the other parts. Here it is also impossible for you to lose what you have earned in a previous part of the experiment.

The first part of the experiment consists of two steps.

\section{Step 1:}

Participants $\mathbf{X}$ and $\mathbf{Y}$ each solve a predetermined number of tasks. Each task consists of determining the correct amount of zeroes in a table consisting of the numbers 0 and 1 . If an incorrect number is given, the participant has up to two more attempts to find the correct number. If the number given is still incorrect after three attempts, the task is considered not completed, and the participant is given a new task. The format of the table (i.e., the number of lines and columns) is the same for all tasks and participants. The tasks are presented to participants $\mathrm{X}$ and $\mathrm{Y}$ on the screens, as in the following example: 
Number of tasks to be solved:

Task No.

Number of tasks solved correctly:

How many zeroes are in this table?

111100111111111

111101101010111

111111101111011

110101011110111

Your answer:

111111011111111

101111111111111

111110111111111

100011000100001

111011111111111

101101101010111 
The respective participant is shown new tasks until the predetermined number of tasks that are to be solved has been reached. The number of tasks to be solved and the Taler earned per task correctly solved are different for participant $\mathbf{X}$ and participant $\mathbf{Y}$, as the following table shows:

\begin{tabular}{|c|c|c|}
\cline { 2 - 3 } \multicolumn{1}{c|}{} & $\begin{array}{c}\text { Number of tasks to be solved cor- } \\
\text { rectly }\end{array}$ & $\begin{array}{c}\text { Taler earned per task correctly } \\
\text { solved }\end{array}$ \\
\hline Participant $\mathbf{X}$ & $\mathbf{1 2}$ & $\mathbf{1 5 0}$ \\
\hline Participant $\mathbf{Y}$ & $\mathbf{4}$ & $\mathbf{5 0}$ \\
\hline
\end{tabular}

In total, thus, participants $\mathrm{X}$ and $\mathrm{Y}$ together accumulate 2000 Taler in this step. The Taler earned are added up.

In the second step, participant A will determine the definitive distribution of the 2000 Taler amongst the participants $\mathrm{X}$ and $\mathrm{Y}$. Participant A does not solve any tasks.

At the end of this step, all participants state which Taler distribution amongst participants $\mathrm{X}$ and $\mathrm{Y}$ they would consider fair.

100-Taler increments are possible here. Each participant hence indicates one of the following distributions:

\begin{tabular}{|c|c|c|}
\hline \multicolumn{2}{|l|}{ eceives } & \\
\hline \multicolumn{2}{|c|}{$\mathrm{X}$ receives 1.900 Taler, $\mathrm{Y}$ receives } & \\
\hline \multicolumn{2}{|c|}{$\mathrm{X}$ receives 1.800 Taler, $\mathrm{Y}$ receives } & \\
\hline \multicolumn{2}{|c|}{$\mathrm{X}$ receives 1.700 Taler, $\mathrm{Y}$ receives } & \\
\hline \multicolumn{2}{|c|}{$\mathrm{X}$ receives 1.600 Taler, $\mathrm{Y}$ receives } & \\
\hline \multicolumn{2}{|c|}{$\mathrm{X}$ receives 1.500 Taler, $\mathrm{Y}$ receives } & \\
\hline \multicolumn{2}{|c|}{$\mathrm{X}$ receives 1.400 Taler, $\mathrm{Y}$ receives } & \\
\hline \multicolumn{2}{|c|}{$\mathrm{X}$ receives 1.300 Taler, $\mathrm{Y}$ rece } & \\
\hline \multicolumn{2}{|c|}{$\mathrm{X}$ receives 1.200 Taler, $\mathrm{Y}$ receives } & \\
\hline \multicolumn{2}{|l|}{$\mathrm{X}$ receives 1} & \\
\hline \multicolumn{3}{|c|}{ ives 1} \\
\hline & \multicolumn{2}{|c|}{900 Taler, Y receives 1.100} \\
\hline & \multicolumn{2}{|c|}{800 Taler, Y receives 1.200} \\
\hline , & \multicolumn{2}{|l|}{700 Taler, Y re } \\
\hline$\lambda$ & \\
\hline & \multicolumn{2}{|l|}{500 Taler, Y receives 1.50} \\
\hline$\gamma$ & \multicolumn{2}{|l|}{400 Taler, $Y$ receives 1.60} \\
\hline , & \\
\hline & \multicolumn{2}{|c|}{200 Taler, $Y$ receives $1.800 \mathrm{~T}$} \\
\hline$x$ & \multicolumn{2}{|l|}{$100 \mathrm{Ta}$} \\
\hline & \multicolumn{2}{|c|}{ ves 2.000} \\
\hline
\end{tabular}

Please note: This information is not shown to any other participant and has no consequences on the payoffs - neither on the own payoffs nor on those of the other participants. 


\section{Step 2:}

Participant A now decides how to distribute fairly among participants $\mathrm{X}$ and $\mathrm{Y}$ the Taler earned by these two participants.

100-Taler increments are possible here. Participant A hence opts for one of the following distributions:

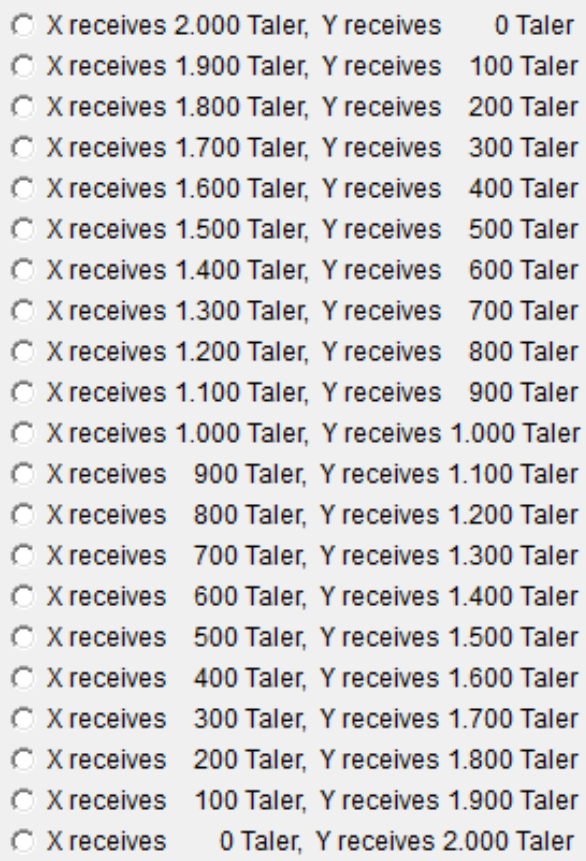

This distribution by participant $\mathbf{A}$ determines the earnings of participants $\mathbf{X}$ and $\mathbf{Y}$ in this part of the experiment.

The first part of this experiment ends with participant A making the decision described above.

Participants $\mathbf{X}$ and $\mathbf{Y}$ are told about the distribution decided upon by participant $\mathbf{A}$ and about their earnings from the first part of the experiment after the end of this experiment.

It is impossible for you to lose, in a later part of the experiment, the earnings you have accumulated in the first part of the experiment.

You will now be shown some control questions on your screen. After you have answered these questions correctly, the first experiment will begin. 


\section{Information on the First Experiment: Part 2}

The participants in this part of the experiment have the same roles as in the first part of the experiment. This means that a participant who had role A in the first part of the experiment will also have role $\mathrm{A}$ in this part of the experiment; a participant who had role $\mathrm{X}$ in the first part of the experiment will also have role $\mathrm{X}$ in this part of the experiment; and a participant who had role $\mathrm{Y}$ in the first part of the experiment will also have role $\mathrm{Y}$ in this part of the experiment. The constellation of the groups also remains the same as in the first part of the experiment. This means participants are always allocated to the same two participants as in the first part of the experiment.

In this part of the experiment, participant $\mathbf{X}$ receives an endowment of $\mathbf{1 0 0 0}$ Taler. The participant decides how many of these 1000 Taler to send to participant $\mathbf{A}$ (any full number between 0 and 1000). Each Taler sent is credited to participant A.

Participant X can make the decision on how many Taler to send dependent on every possible Taler distribution chosen by participant $A$ in the first part of the experiment. The actual distribution from the first part of the experiment is told to participant $\mathbf{X}$ only after the experiment has ended. However, $\mathrm{X}$ has to decide in this part of the experiment how many Taler he or she wishes to send for every possible distribution.

In this part of the experiment, participant $\mathbf{X}$ must therefore fill in the following decision table:

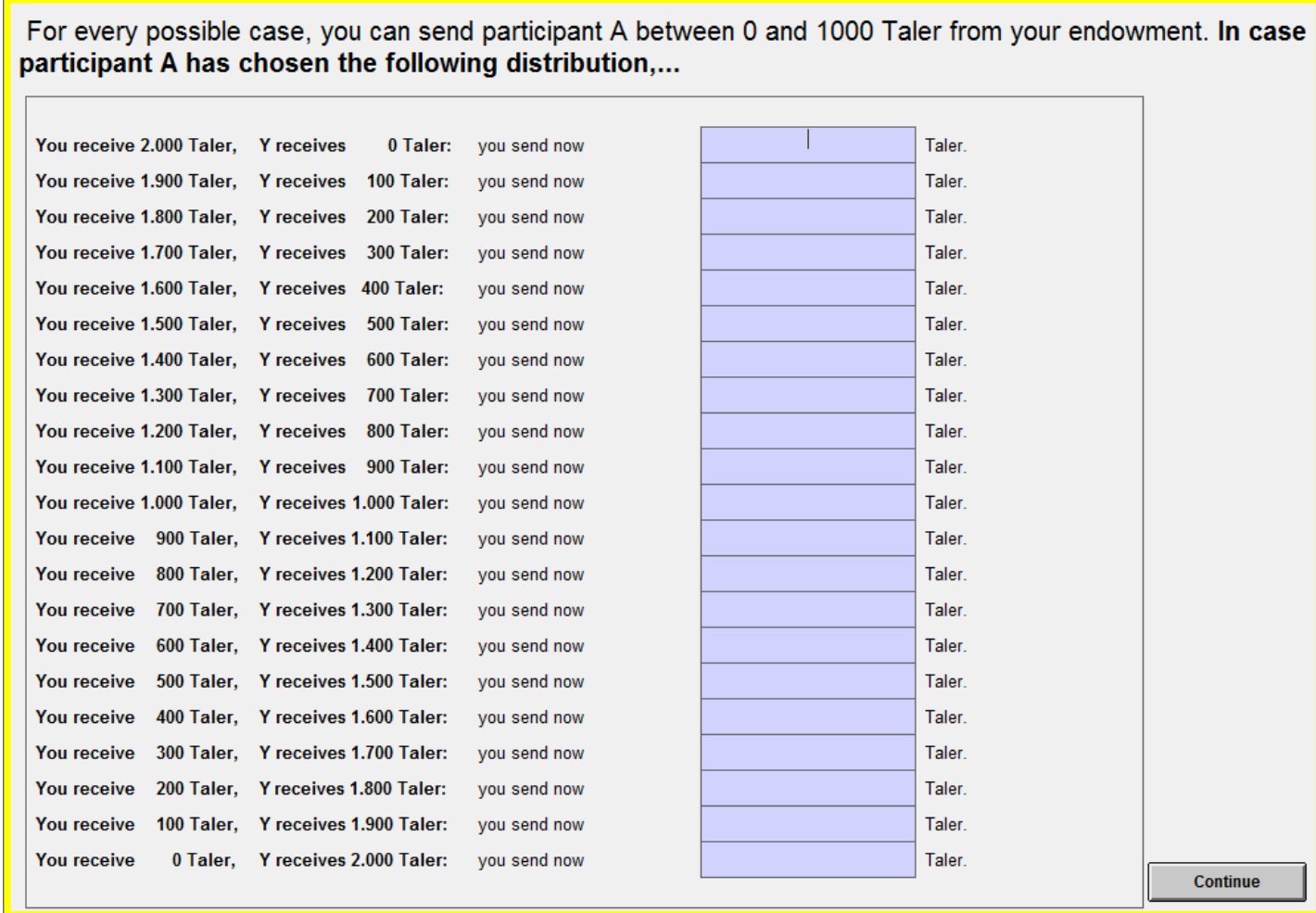


Participant $\mathbf{X}$ may enter any full number between 0 and 1000 in every line. The only line that becomes payoff-relevant is the one that corresponds to the distribution actually chosen by $A$ in the first part of the experiment. The decisions in the other lines do not influence the participants' payments. The lines do not have to add up exactly to 1000 either, as the only decision-relevant line is the one that corresponds to the actual situation.

As participant $\mathbf{X}$, please note that at the time of filling in the table you do not yet know which decision participant A has made in the first part of the experiment. You therefore have to consider your decision very carefully in every line, because any of the lines could become payoff-relevant for you.

After filling in the table, participants $\mathrm{X}$ and $\mathrm{Y}$ will be given a brief questionnaire.

Participant $\mathbf{Y}$ makes no decisions in this part of the experiment and receives no earnings. Participant A makes no decisions either in this part of the experiment.

The earnings from this experiment add up as follows:

\begin{tabular}{|l|c|}
\hline & Taler sent by X to A \\
Participant A & (in the payoff-relevant situation) \\
\hline Participant $\mathbf{X}$ & 1.000 Taler - Taler sent by X to A \\
& (in the payoff-relevant situation) \\
\hline
\end{tabular}

After filling in the questionnaire, the second part of the experiment ends.

Only after the experiment has ended are participants given information on the actual distribution decision of participant $\mathbf{A}$ in the first part of the experiment and on the sum corresponding to this distribution, which participant $\mathbf{X}$ has sent to participant $\mathrm{A}$ in this part of the experiment.

It is impossible for you to lose, in a later part of the experiment, the earnings you have accumulated in the first and second part of the experiment.

You will now be shown some control questions on your screen. After you have answered these questions correctly, the second part of the experiment will begin. 


\section{Information on the First Experiment: Part 3}

The participants in this part of the experiment have the same roles and the same group as in the first two parts of the experiment.

In this part, participants $\mathbf{X}$ and $\mathbf{Y}$ estimate which distribution they think participant $\mathbf{A}$ has opted for in the first part of the experiment.

Each participant who correctly estimates the exact distribution chosen by participant A receives 200 Taler. If the estimate is incorrect, albeit straying merely by one decision possibility from participant A's actual decision, then the participant earns 50 Taler. A deviation by one decision possibility means that participant A actually gave participant X 100 Taler more (or less) and participant Y 100 Taler less (or more) than estimated. If the estimate deviates even more from participant A's actual decision, then the participant receives no further earnings from the estimate. The earnings from this part of the experiment are hence calculated in the following manner:

\begin{tabular}{|c|c|}
\hline Possible scenario & Earnings from Estimate \\
\hline Correct estimate & 200 Taler \\
\hline $\begin{array}{c}\text { Overrated X's earnings by 100 } \\
\text { Taler and underrated Y's earn- } \\
\text { ings by 100 Taler }\end{array}$ & 50 Taler \\
\hline $\begin{array}{c}\text { Underrated X's earnings by 100 } \\
\text { Taler and overrated Y's earnings } \\
\text { by 100 Taler }\end{array}$ & 50 Taler \\
\hline $\begin{array}{c}\text { Stronger deviation (more than } \\
\text { 100 Taler) from the estimate }\end{array}$ & 0 Taler \\
\hline
\end{tabular}

In this part of the experiment, the earnings of a participant who makes an estimate depend only on the correct estimate. No participant can influence in any way, in this part of the experiment, the earnings of another participant. The earnings of a participant in this part of the experiment do not depend on the earnings of another participant in this part of the experiment.

In this part of the experiment, participant $\mathbf{A}$ makes no decision and receives no earnings.

\section{The first experiment ends after these decisions.}

All participants are then told the decisions made by the members of their group that are payoff-relevant to them, as well as their earnings from the individual parts of the experiment. After this, we would then ask you please to fill in a brief questionnaire.

A further experiment will follow. Here, it will not be possible for participants to interact once again with the same participants from the first experiment. Further, as before, participants will not be able to lose their earnings from previous experiments in the following experiments. 


\section{Information on the Second Experiment}

In the following, we would ask you please to make your own decisions. In order to do this, you will be randomly matched with another participant. In several distribution decisions, you can give this other participant and yourself points. For this to happen, you will have to choose repeatedly between two distributions, "A" and "B". The points you give yourself are paid out to you at the end of the experiment, at a rate of 250 points $=\mathbf{1} €$. At the same time, you are also randomly matched with another experiment participant, who also distributes points to you by choosing distributions. This participant is not the same participant as the one to whom you may distribute points. The points given to you are also credited to your account. The sum of all points you allocate to yourself and those allocated to you is paid out to you at the end of the experiment, at a rate of 250 points $=1 €$.

Please note that the participants matched with you in this part of the experiment are no members of your group from the preceding part of the experiment. You are hence matched with other participants in this case.

The individual decision tasks will look like this:

\begin{tabular}{|c|c|c|c|}
\hline \multicolumn{2}{|c|}{ Possibility A: } & \multicolumn{2}{c|}{ Possibility B: } \\
\hline Your points & $\begin{array}{c}\text { The points of the exper- } \\
\text { iment participant allo- } \\
\text { cated to you }\end{array}$ & Your points & $\begin{array}{c}\text { The points of the exper- } \\
\text { iment participant allo- } \\
\text { cated to you }\end{array}$ \\
\hline 0 & 500 & 304 & 397 \\
\hline
\end{tabular}

A

\section{B}

In this example: If you clicked "A", you would give yourself 0 points and 500 points to the experiment participant allocated to you. If you clicked "B", you would give yourself 304 points and 397 points to the experiment participant allocated to you.

Subsequently we will ask you to fill in some questionnaires. While you do this, we will prepare your payments. 


\section{B.2 Instructions Voice}

In Experiment 1 Part 1 an additional Step is introduced in the instructions after Step 1:

In Step 2, participant $\mathbf{X}$ has the chance to send participant $\mathbf{A}$ a message. If you are a participant $\mathbf{X}$, please follow the instructions about this on your screen. The participants $\mathbf{Y}$ and $\mathbf{A}$ have no possibility to send a message.

\section{B.3 Screenshot Narrow Voice Treatment}

The additional step looked as follows. Screenshots are translated into English. They have not been printed in the instructions.

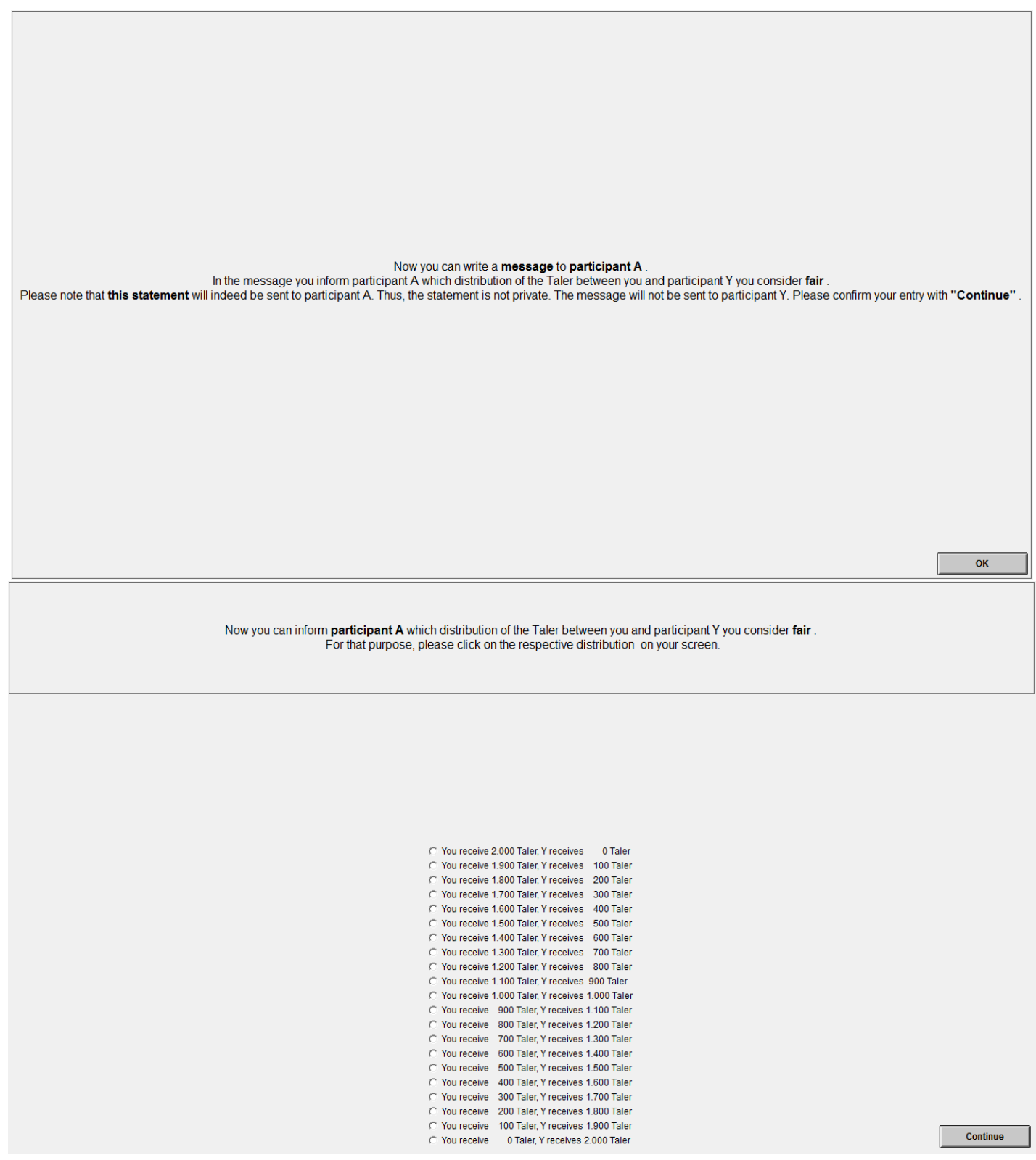




\section{B.4 Screenshots Broad Voice Treatment}

The additional step looked as follows. Screenshots are translated into English. They have not been printed in the instructions.

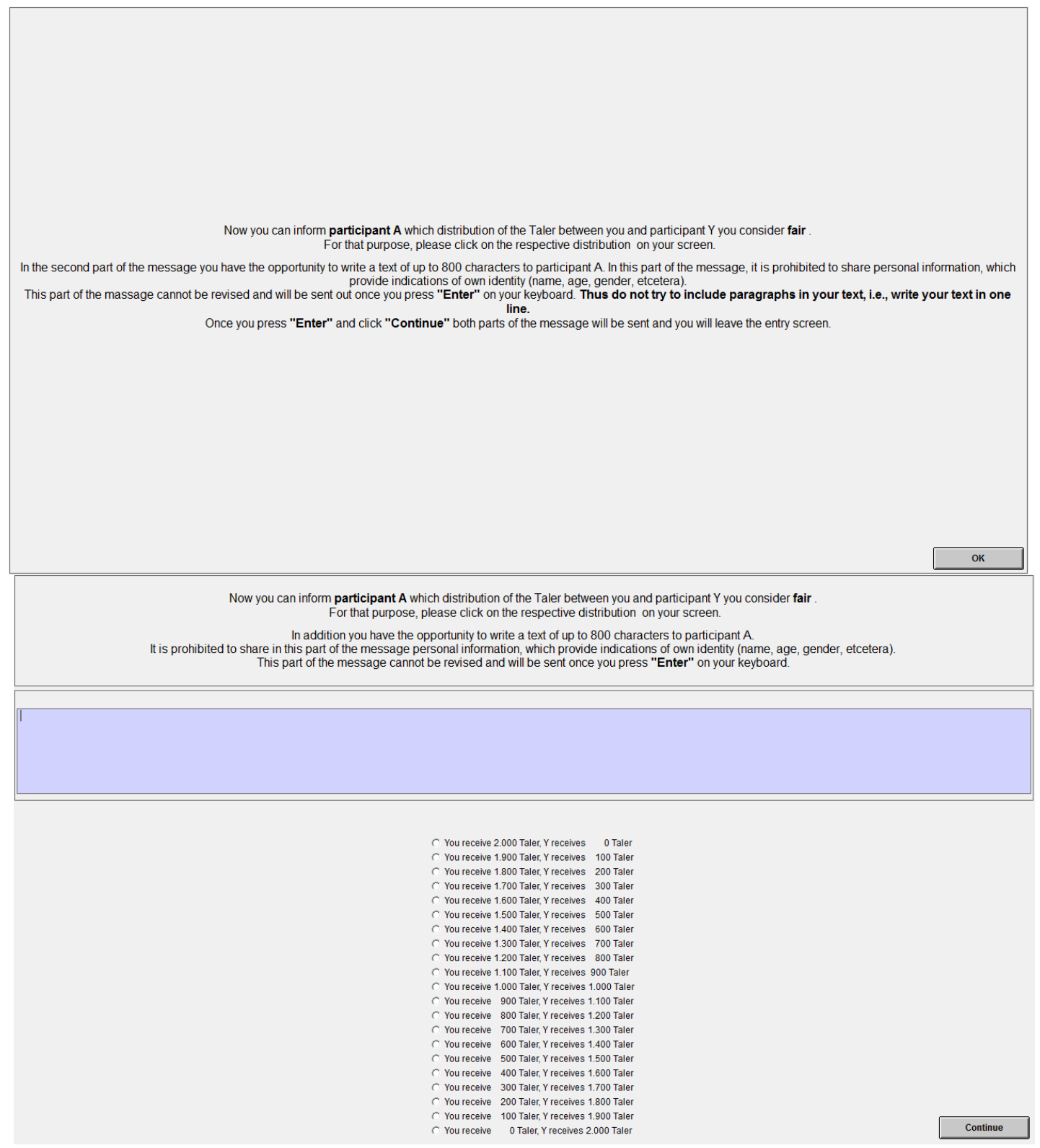




\section{B.5 Instructions Uninvolved Treatments}

The instructions of the both uninvolved treatments only differ to the other treatments in the second part of the first experiment:

\section{Information on the First Experiment: Part 2}

The participants in this part of the experiment have the same roles as in the first part of the experiment. This means that a participant who had role A in the first part of the experiment will also have role $\mathrm{A}$ in this part of the experiment; a participant who had role $\mathrm{X}$ in the first part of the experiment will also have role $\mathrm{X}$ in this part of the experiment, and a participant who had role $\mathrm{Y}$ in the first part of the experiment will also have role $\mathrm{Y}$ in this part of the experiment. Additionally, the non-profit organization "Deutsche Welthungerhilfe e.V." will be relevant in this part of the experiment. This organization is active in the field of development organization and is officially certified by the German Central Institute for Social Issues.

In this part of the experiment, player $\mathbf{X}$ receives an endowment of $\mathbf{1 0 0 0}$ Taler. The player decides how many of these 1000 Taler to send to the non-profit institution (any full number between 0 and 1000). Each Taler sent is credited to the non-profit institution.

Player X can make the decision on how many Taler to send dependent on every possible Taler distribution chosen by player $A$ in the first part of the experiment. The actual distribution from the first part of the experiment is told to player $\mathbf{X}$ only after the experiment has ended. However, $\mathrm{X}$ has to decide in this part of the experiment how many Taler he or she wishes to send for every possible distribution.

In this part of the experiment, player $\mathbf{X}$ must therefore fill in the following decision table: 


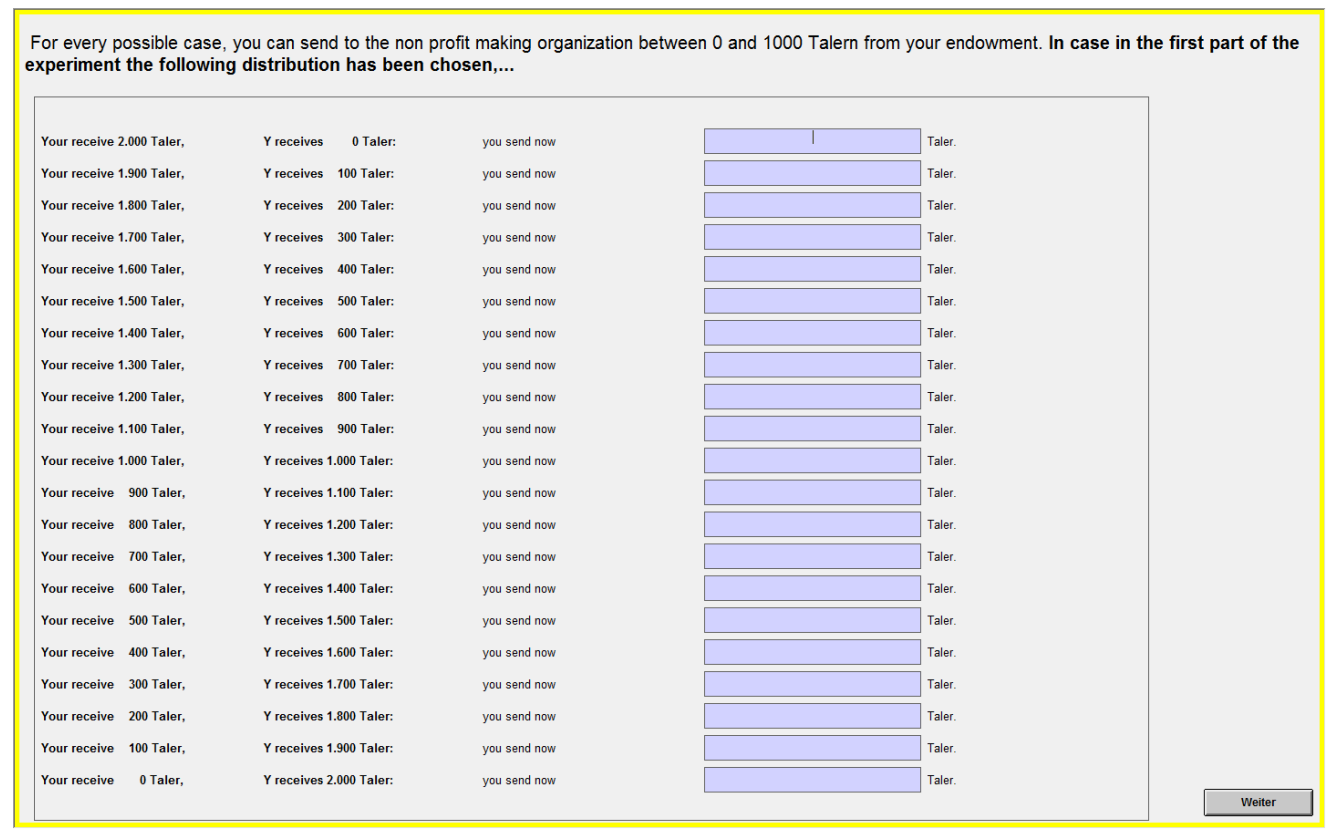

Participant X may enter any full number between 0 and 1000 in every line. The only line that becomes payoff-relevant is the one that corresponds to the distribution actually chosen in the first part of the experiment. The decisions in the other lines do not influence the participants' payments. The lines do not have to add up exactly to 1000 either, as the only decisionrelevant line is the one that corresponds to the actual situation.

As participant $\mathrm{X}$, please note that at the time of filling in the table you do not yet know which allocation decision has been made in the first part of the experiment. You therefore have to consider your decision very carefully in every line, because any of the lines could become payoff-relevant for you.

After filling in the table, participants $\mathrm{X}$ and $\mathrm{Y}$ will be given a brief questionnaire.

Player Y and player A make no decisions in this part of the experiment and receive no earnings.

The earnings from this experiment add up as follows:

\begin{tabular}{|c|c|}
\hline & 1.000 Taler - Taler sent by X to the non-profit institution \\
Participant $\mathbf{X}$ & (in the payoff-relevant situation) \\
\hline
\end{tabular}

After filling in the questionnaire, the second part of the experiment ends.

Only after the experiment has ended are participants given information on the actual distribution decision of player $\mathbf{A}$ in the first part of the experiment and on the sum corresponding to this distribution, which player $\mathbf{X}$ has sent to the non-profit institution in this part of the experiment. 
It is impossible for you to lose, in a later part of the experiment, the earnings you have accumulated in the first and second part of the experiment.

The Taler sent to the non-profit institution will be converted into Euro at the rate stated above and will be transferred by the experimenters after the end of all experimental sessions. After the end of today's experiments, a web address will be shown to all participants, where proof of the total amount donated in all experimental sessions will be displayed from 17 March 2013 onwards.

You will now be shown some control questions on your screen. After you have answered these questions correctly, the second part of the experiment will begin. 


\section{Appendix C. Non-incentivized questions to player $\mathbf{X}$}

Directly after the dictator game for every possible allocation, separately:

"Please tell us now how happy you are with the respective possible distributions. In case the role A participant has chosen the following distribution, you receive 0 Taler, Y receives 2000 Taler, are you completely happy / not at all happy?"

At the end of the experiment:

"What influence do you think you had on participant A's decision?"

"In your opinion, how fair is the way in which the decision was made?"

"How fair do you consider the process from the point-of-view of participant X?"

"How fairly do you consider yourself treated in the process leading to the decision?"

"In your opinion, how fair is the distribution, chosen by participant A, between yourself and participant Y?”

"To what degree do you accept the distribution, chosen by participant A, between yourself and participant Y?"

"How fair do you consider the process from the point-of-view of a participant Y?"

"In your opinion, how legitimate is participant A's decision?"

"In your opinion, how legitimate is the fact that the participant decided on the Taler distribution?"

Baseline, only: "How important would it have been to you to have the chance to send participant A a message in which you state the distribution you would have considered as fair?"

Narrow and broad voice treatments, only: "How important was it to you to have the chance to send participant A a message in which you state the distribution you would have considered as fair?"

Baseline and narrow voice treatment, only: "How important would it have been to you to have the chance to send participant A a message in the guise of a freely formulated text?"

Broad voice treatment, only: "How important was it to you to have the chance to send participant A a message in the guise of a freely formulated text?"

Questions on subjects' general obedience to the law according to Tyler (2006), p. 46.

Questions on subjects' reciprocity taken from the German Socio-Economic Panel Study (SOEP) 
Socio-demographics (age, gender, no. of siblings, experience in experiments, field of study, duration of study, native language, latest school grade in mathematics, currently employed for more than 10 hours per week, monthly income)

Questions to be answered free form (e.g., aim of the experiment, something subjects want to tell to the experimenter) 